\title{
The Relieving Effects of BrainPower Advanced, a Dietary Supplement, in Older Adults with Subjective Memory Complaints: A Randomized, Double-Blind, Placebo-Controlled Trial
}

\author{
Jingfen Zhu, ${ }^{1}$ Rong Shi, ${ }^{2}$ Su Chen, ${ }^{3}$ Lihua Dai, ${ }^{4}$ Tian Shen, ${ }^{1}$ Yi Feng, ${ }^{1}$ Pingping Gu, ${ }^{5}$ \\ Mina Shariff, ${ }^{6}$ Tuong Nguyen, ${ }^{6}$ Yeats Ye, ${ }^{7}$ Jianyu Rao, ${ }^{8}$ and Guoqiang Xing ${ }^{9,10}$ \\ ${ }^{1}$ Department of Community Health and Family Medicine, School of Public Health, Shanghai Jiao Tong University, \\ Shanghai 200025, China \\ ${ }^{2}$ School of Public Health, Shanghai University of TCM, Shanghai 201203, China \\ ${ }^{3}$ Si-Tang Community Health Service Center of Shanghai, Shanghai 200431, China \\ ${ }^{4}$ Department of Emergency Medicine, Xin Hua Hospital Affiliated to Shanghai Jiao Tong University School of Medicine, \\ Shanghai 200092, China \\ ${ }^{5}$ Southern California Kaiser Sunset, 4867 Sunset Boulevard, Los Angeles, CA 90027, USA \\ ${ }^{6}$ Department of Research, DRM Resources, 1683 Sunflower Avenue, Costa Mesa, CA 92626, USA \\ ${ }^{7}$ Maryland Population Research Center, University of Maryland, College Park, MD 20742, USA \\ ${ }^{8}$ Department of Pathology and Laboratory Medicine, David Geffen School of Medicine, University of California at Los Angeles, \\ Los Angeles, CA 90095, USA \\ ${ }^{9}$ Imaging Institute of Rehabilitation and Development of Brain Function, North Sichuan Medical University, \\ Nanchong Central Hospital, Nanchong 637000, China \\ ${ }^{10}$ Lotus Biotech.com LLC, John Hopkins University-MCC, 9601 Medical Center Drive, Rockville, MD 20850, USA
}

Correspondence should be addressed to Rong Shi; shirong61@163.com and Guoqiang Xing; gxing99@yahoo.com

Received 18 December 2015; Revised 27 February 2016; Accepted 29 February 2016

Academic Editor: Jairo Kennup Bastos

Copyright (C) 2016 Jingfen Zhu et al. This is an open access article distributed under the Creative Commons Attribution License, which permits unrestricted use, distribution, and reproduction in any medium, provided the original work is properly cited.

Subjective memory complaints (SMCs) are common in older adults that can often predict further cognitive impairment. No proven effective agents are available for SMCs. The effect of BrainPower Advanced, a dietary supplement consisting of herbal extracts, nutrients, and vitamins, was evaluated in 98 volunteers with SMCs, averaging 67 years of age (47-88), in a randomized, double-blind, placebo-controlled trial. Subjective hypomnesis/memory loss (SML) and attention/concentration deficits (SAD) were evaluated before and after 12-week supplementation of BrainPower Advanced capsules $(n=47)$ or placebo $(n=51)$, using a 5-point memory questionnaire $(1=\mathrm{no} / \mathrm{slight}, 5=$ severe $)$. Objective memory function was evaluated using 3 subtests of visual/audio memory, abstraction, and memory recall that gave a combined total score. The BrainPower Advanced group had more cases of severe SML $($ severity $\geqslant 3)(44 / 47)$ and severe SAD $(43 / 47)$ than the placebo group $(39 / 51$ and $37 / 51,<0.05,<0.05$, resp.) before the treatment. BrainPower Advanced intervention, however, improved a greater proportion of the severe SML $(29.5 \%)(13 / 44)(P<0.01)$ and SAD $(34.9 \%)(15 / 43)(P<0.01)$ than placebo (5.1\% (2/39) and 13.5\% (5/37), resp.). Thus, 3-month BrainPower Advanced supplementation appears to be beneficial to older adults with SMCs.

\section{Introduction}

Memory is the ability of an individual to record, retain, and recall sensory stimuli, events, and information over short and long periods of time. Deficits in memory function can compromise one's quality of life and ability to work.

Hypomnesis/forgetfulness/memory decline can occur with aging or as results of subhealth conditions [1]. Complaints 
about memory impairment, or subjective memory complaints (SMCs), are common in elderly people but are rarely detected by clinicians using objective memory function tests due to the subtle and heterogeneous nature of SMC [2-5]. SMCs are a criterion of mild cognitive impairment (MCI), which is common in older adults and in people who have experienced subhealth conditions [6-12].

MCI is an intermediary status between normal aging and prodromal memory decline $[6,13]$. Individuals with MCI appear to have intact general cognitive function and activities of daily living, but their memory is impaired for normal age. The prevalence of MCI is estimated at 3\%-19\% in adults older than 65 years and $15 \%$ in adults older than 75 years [14-18]. Less than half of people with MCI are stable or able to reverse back to normal memory function again within 5 years [1921].

SMC and MCI are often associated with a decline in episodic memory (a recollection of specific past events) [2224], which is most frequently found in those with the amnesic subtype MCI [22-28]. Positron emission tomography (PET) brain image studies show that people with SMC are characterized with elevated brain beta-amyloid [25-27]. Increased amyloid deposition has an early and subclinical impact on cognition that precedes hypometabolism [28] and impairs blood vessel functions [29] that could contribute to increased inflammation in amnestic mild cognitive impairment [30].

Latent insufficiency of cerebrovascular circulation and loss of phospholipid asymmetry may underlie early manifestation of SMC and MCI [31] and could be a risk factor for episodic nonspecific complaints of mild cognitive deficit, regional hypoperfusion, and hypometabolism [32-38].

Episodic memory processes depend on the integrity of the medial temporal lobe, hippocampus, the posterior parietal cortex, and lateral prefrontal cortex (PFC) [33-35]. Imaging studies have shown an asymmetric hemispheric encoding/retrieval (HERA) pattern in young adults where the left PFC and temporo-occipital cortex are involved in encoding and the right $\mathrm{PFC}$ is involved in retrieval of the stored information [36-39]. During normal aging, PFC activation becomes less asymmetric during memory tasks. Normal or high-performing older adults balance age-related neural decline through neuroplasticity, which reorganizes neurocognitive networks. The subnormal or low-performing older adults use a network similar to young adults, but inefficiently $[36,40]$.

Abnormal cholinergic and glutamatergic neurotransmissions are thought to be involved in SMC and MCI [4143]. Cognitive decline in older adults is associated with a loss of cholinergic function (cholinergic hypofunction) including a reduction in choline acetyltransferase (ChAT), muscarinic and nicotinic acetylcholine receptor binding sites, and concentrations of acetylcholine in the synaptic clefts $[43,44]$. Glutamatergic overstimulation (excitotoxicity) of the postsynaptic NMDA receptors could also lead to memory impairment [45].

Currently, there are no effective and safe pharmaceutical drugs for SMC and MCI. Prevention of the progression of the symptomatic development could be the best strategy [46]. Although acetylcholinesterase inhibitors (AChEIs) and
$\mathrm{N}$-methyl D-aspartate (NMDA) receptor antagonists have been used for treatment of people with varying degree of memory deficits, their effects on cognition and memory improvement are often negative [47-54]. A portion of people with MCI, however, may respond favorably to AChEIs (15\%$35 \%)$ and NMDA receptor antagonists (30\%) [55-57], but usually after high doses or long treatment, and with potential adverse effects, such as nausea, vomiting, diarrhea, headache, hypertension, and hepatotoxicity [58-64].

A variety of plant-derived compounds have been studied as potential enhancers of memory and cognitive function [65] with potential mechanisms on (1) modulation of neuronal membrane integrity; (2) modulation of the cholinergic system through inhibition of acetylcholinesterase (AChE) or stimulation of muscarinic and nicotinic receptors; (3) neuroprotection against NMDA receptor excitotoxicity; (4) anti-inflammatory and antioxidant activities; (5) improved cerebral blood flow and microperfusion.

Table 1 lists some herbal extracts and compounds that are active ingredients of BrainPower Advanced, the formulation used in this pilot study. BrainPower Advanced is a dietary supplement formulated to support healthy memory and cognitive function in adults. Its key ingredients include extracts of Ginkgo biloba (flavonoids, terpenoids, and terpene lactones), Camellia sinensis leaf (tea polyphenols), Catharanthus roseus (vinpocetine), kola nut (Cola nitida, caffeine), Huperzia serrata (hup A and hup B), phosphatidylserine (PS), L-tyrosine, L-pyroglutamic acid, acetyl-L-carnitine, choline bitartrate, L-glutamine, L-phenylalanine, L-cysteine, vitamin B6, and vitamin B12 (Table 1).

PS is a key integrative phospholipid component of neuronal cell membranes and represents $15 \%$ of the total phospholipid pool. PS acts to maintain membrane integrity and neuroplasticity, buffer oxidative stress, facilitate neurotransmitter release, and increase brain glucose metabolism [66-69]. Phospholipid deficits in neuronal membranes are involved in age-related brain-structural and cognitive decline. A decline of PS and other phospholipids in neuronal membranes has been associated with memory impairment and cognitive deficits whereas dietary PS and phospholipid supplements have prevented or reversed such deficits [7075]. PS supplementation improved learning capacity and memory in rodents [76, 77] and improved physical and mental performance such as long-term memory and recognition in elderly people with cognitive decline [73, 78-80], in stressed young adults [81], and in children with attention deficit hyperactivity disorder [82].

Vinpocetine (ethyl apovincaminate) is synthesized from the alkaloid vincamine, an extract from the leaf of the lesser periwinkle plant (Catharanthus roseus). Vinpocetine has been used widely in Japan and Europe for the treatment of cognitive decline since the late 1970s. Vinpocetine can improve cerebral blood flow and glucose metabolism in the thalamus and basal ganglia and the occipital, parietal, and temporal cortex [83-86]. Previous studies have confirmed that vinpocetine can inhibit beta-amyloid-induced activation of NF- $\kappa \mathrm{B}$, inflammation, and cytokine production and interferes with many stages of the ischemic cascade: ATP depletion, activation of voltage-sensitive $\mathrm{Na}(+)$ and $\mathrm{Ca}(++)$ 


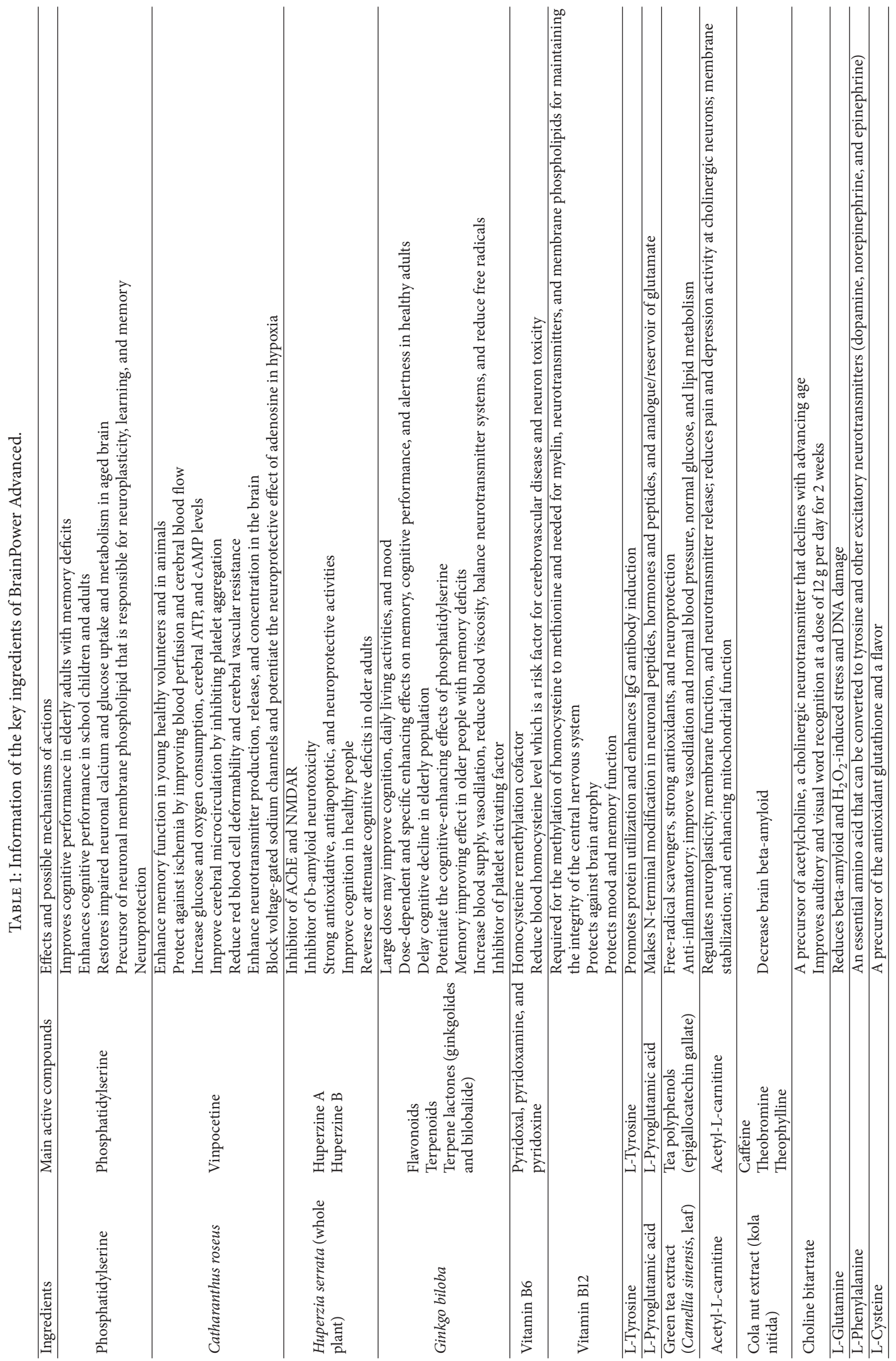


channels, and glutamate and free-radical release (antioxidant activity) [87-91]. Vinpocetine treatment for 18 months significantly improved cognitive functions, overall health status, and quality of life in people with chronic cerebral hypoperfusion [92]. Vinpocetine is considered prophylactic for MCI [92-94].

Huperzine A (hup A), is a quinolizidine-related alkaloid isolated from Huperzia serrata (Thunb.) Trevis. Hup A is a competitive, reversible, and well-tolerated inhibitor of $\mathrm{AChE}$ that is more potent than current memory-promoting agents (donepezil, rivastigmine, and galantamine) [95-98]. Hup A is also a competitive NMDA receptor inhibitor and an antagonist of $A \beta$-induced neurotoxicity [99-108]. It has significant antioxidative, antiapoptotic, and neuroprotective effects [100]. Hup A has been used for enhancing memory and mental function in healthy people [101] and in animal models of cognitive deficits [97] without showing any obvious serious adverse effects [102]. Other studies suggest, however, that hup A has limited effects on cognition. One recent multicenter, randomized, placebo-controlled trial showed that a dose of $0.4 \mathrm{mg}$ daily, but not $0.2 \mathrm{mg}$ daily, of hup A was effective in improving cognition in people with moderate cognition decline [103].

The active components of the leaf extract of Ginkgo biloba (EGb) consist of flavonoids, terpenoids, and terpene lactones (ginkgolides and bilobalide). EGb has long been used in traditional Chinese medicine [104, 105]. EGb has also been prescribed for memory and concentration complaints in Germany and France since the 1960s [106, 107]. EGb protects neuronal cell membranes and mitochondria from free-radical damage [108]; reduces the aggregation and toxicity of beta-amyloid [109, 110]; promotes hippocampal neurogenesis [111-116]; decreases blood viscosity [117, 118]; enhances microperfusion [119]; improves neurotransmission of glutamatergic [120-122], dopaminergic, and cholinergic systems [123, 124]; and improves learning and memory in animal models [125-129].

Recent meta-analyses of multiple randomized, controlled trials suggest that EGb may be effective for reversing or delaying age-related memory deficits [130-135]. However, two recent large-scale studies, conducted in more than 6000 participants aged 70 years and over [136, 137], failed to confirm such effects. One explanation is that, due to the particularly long incubation phase of severe memory decline (20-30 years), a quick reduction in the incidence of severe memory deficits by EGb is unrealistic, or EGb is only effective in subjects at early stages of memory decline such as SMC and/or MCI, but not in advanced stage of memory deficits. To support this, short-term and acute EGb administration could be used to enhance specific memory and cognitive functions in cognitively intact older, middle-aged, and younger healthy volunteers [138]. In addition, coadministration of EGb and PS improved secondary memory and the speed of memory task performance $[125,126]$.

Other studies show that deficits or dysregulation in brain metabolism is linked with aging-related cognition decline and that decline could be reversed through nutrients and vitamin supplements such as acetyl-L-carnitine, vitamin B6, and vitamin B12 [139-151]. L-Tyrosine is a precursor to
L-dopa and catecholamines, an imbalance of which may be involved in cognitive dysfunction $[127,128]$.

The preventive effects of coffee, tea, and caffeine consumption on late-life cognitive decline and dementia have been extensively reviewed recently [129]. Besides the wellknown short-term enhancing effects, some studies examined the long-term effects and showed that coffee, tea, and caffeine consumption could protect against late-life cognitive impairment/decline and dementia. These findings, however, are still considered preliminary [129].

Green tea (Camellia sinensis) extract enhances parietofrontal connectivity during working memory processing [152] and protects against okadaic acid-induced acute learning and memory impairments in rats [153]. A recent review suggests that the green tea constituent theanine could have therapeutic effects against psychiatric and neurodegenerative disorders including mild cognitive impairment and dementia through multiple mechanisms such as inhibition of NMDAinduced neurotoxicity, enhanced brain GABA and glycine content, and enhanced BDNF-related neuroprotection [154]. Most of these mechanistic studies, however, were done on animals.

Coadministration of multiple medicinal herbal ingredients is a common practice in traditional Chinese medicine. The main goal of such practices is to potentiate the bioavailability, activity, and efficacy of the key therapeutic ingredients and to minimize or antagonize potential toxicities associated with the ingredients.

The objective of this exploratory, randomized, placebocontrolled trial was to evaluate the safety and effectiveness of short-term administration of BrainPower Advanced, a multiingredient dietary supplement, on SMCs in older adults.

\section{Methods}

2.1. Samples and Participants Recruitment. This study was conducted between December 15, 2011, and April 10, 2012, at the Si Tang Community Health Service Center in Baoshan district in Shanghai, China. Community volunteers of older adults were recruited by self-referral in response to media coverage and word of mouth. All study procedures were conducted in accordance with the Helsinki Declaration of 1975 and were approved by the Shanghai Jiao Tong University Medical Center Institutional Review Board. Informed consent was obtained from all participants prior to enrollment into the study.

Subjects who met the following criteria were eligible for the study: inclusion criteria: (1) healthy males or females at least 50 years of age; (2) having self-reported hypomnesis, forgetfulness, memory loss, or impaired attention/concentration as determined by a standard medical examination questionnaire; exclusion criteria: (1) having been diagnosed with neurological diseases such as Alzheimer's Disease, Parkinson's Disease, migraine, and epilepsy; (2) having taken any medication likely to affect brain and nervous system function such as L-dopa, MAO inhibitors, modafinil, and amphetamine, within 30 days before the start of the trial; (3) having a history of severe cerebral-cardiovascular events 
(myocardial infarction, cerebrovascular disorder, acute coronary syndrome, or other cerebrovascular diseases); (4) other severe medical conditions (severe diseases of the liver, kidneys, or lungs; malignant tumors; motor impairment; dysphonia; visual impairment; etc.).

2.2. Randomization and Blindness. Participants were randomly assigned to the BrainPower Advanced treatment group or placebo treatment group. The randomization was performed using a predetermined randomization code which was generated by a random number generator. The numbers generated were placed in sealed envelopes and a serial number was assigned to each envelope according to the sequence of allocation of the randomized number. Each envelope was then opened sequentially according to the admission sequence of subjects.

Trial participants and community doctors were both blinded from the treatment (double-blind trial). Of the 101 enrolled participants, 98 participants completed the 12-week follow-up, including 47 subjects in the BrainPower Advanced group and 51 subjects in the placebo group. Three subjects withdrew from the study ( 2 due to symptoms of diarrhea and 1 due to family objection).

The participants received similar-looking capsules in color-coded bottles (white bottles for BrainPower Advanced and yellow bottles for placebo). Neither the subjects nor the medical doctors, including the study principal investigator (Rong Shi), knew the specific color code until the end of the study. Both the BrainPower Advanced capsules and the placebo (which was mainly composed of flour) were manufactured and supplied by Robinson Pharma, Inc. (Costa Mesa, California, USA).

Each participant was instructed to take 2 capsules with meals daily for 12 weeks and a new batch of supplements was dispensed every 4 weeks during follow-up sessions. Changes in subjective hypomnesis/memory loss and attention/concentration deficits were recorded using a self-administrated medical questionnaire. Memory function capacity was evaluated using a subset of tester-administered memory tests before and after the 12-week intervention. All participants were followed up each month in order to check compliance and adverse effects.

2.3. Evaluation of Subjective Memory Complaints. Two aspects of subjective memory complaints, that is, subjective hypomnesis/forgetfulness/memory loss (SML) and subjective attention/concentration deficits (SAD), were screened using a self-administered 5-point scale $(1=$ no symptoms or occasional slight symptoms complaints; $2=$ slight $/$ mild symptom complaints; 3 = moderate severe symptom complaints; $4=$ severe symptom complaints; $5=$ very severe symptom complaints) included in a medical questionnaire that included the demographics and medication history of the participants. Because relatively few participants scored 1 and 2 points in the memory questionnaire, participants who scored 1 and 2 points were combined as the "slight symptom" group, and participants who scored 3, 4, and 5 points were combined as the "severe symptom" group for further statistical analysis.
2.4. Evaluation of Objective Memory Function. The shortterm working memory of the participants was evaluated using three simple tester-administered subtests constructed and validated for the Chinese population [155].

(1) Visual/Auditory Memory (1 Point for Each Correct Answer, a Maximal Total of 5 Points). Subjects were allowed to watch 5 film clips in 5 minutes ( 1 minute per film clip). The films were selected from a pool of popular old Chinese films that all participants should have been familiar with. The subjects were then asked to recall the correct order and content of the films based on the movie listings provided by the tester.

(2) Abstracting (1 Point for Each Correct Answer, a Maximal Total of 5 Points). Subjects were shown 5 different pictures/images of cartoon characters (such as a policeman, soldier, medical doctor, nurse, taxi driver, bus driver, school teacher, university professor, cook, waitress, and tour guide) on a computer screen and were asked to recall them immediately.

(3) Memory Recall (1 Point for Each Correct Answer, a Maximal Total of 5 Points). Subjects were shown 5 consecutive pictures of famous historical landscapes located in different Chinese cities and were asked to recall the pictures' contents and their locations.

2.5. Statistics Analysis. EpiData 3.02 software was used for the establishment of the database. SPSS 20.0 software was used for statistical analysis. Group data were presented as the mean \pm s.d. Mean differences of the variables between the BrainPower Advanced and placebo groups were compared using Student's $t$-test for variables with normal distribution or using nonparametric tests for variables with nonnormal distributions. Ridit scoring test, which is a nonparameter test for comparing two or more sets of ordered qualitative data, was used for evaluating the changes in the symptom severity score of SML and SAD in response to the intervention. The alpha level of $P>0.05$ was chosen as being statistically significant. All $P$ values reported were 2 -sided.

\section{Results}

3.1. Participants' Characteristics. The baseline characteristics of age and gender and histories of alcohol intake, disease, and medication of the participants are shown in Table 2. There were 14 males (29.8\%) and 33 females (70.2\%) in the BrainPower Advanced group and 17 males (33.3\%) and 34 females $(66.7 \%)$ in the placebo group. The gender distribution between the two groups was not significantly different $\left(\chi^{2}=\right.$ $0.142, P>0.05)$, with females accounting for more than twothirds of the total participants. The overall average age of all participants was $67.1 \pm 10.5$, with no significant difference found between the BrainPower Advanced group (69.1 \pm 9.5 years $)$ and the placebo group $(65.2 \pm 11.1$ years $)(t=1.839$, $P>0.05)$. The BrainPower Advanced and placebo groups also showed similar patterns of alcohol intake history $\left(\chi^{2}\right.$ $=0.542, P>0.05)$. However, a greater proportion of the participants in the BrainPower Advanced group had disease 
TABLE 2: Demographics and medical history of the participants $(N=98)$.

\begin{tabular}{|c|c|c|c|c|}
\hline & Treatment & Male & Female & Subtotal \\
\hline \multirow{3}{*}{ Gender, $N$ (\% of subtotal) } & BrainPower & $14(29.8 \%)$ & $33(70.2 \%)$ & $47(100 \%)$ \\
\hline & Placebo & $17(33.3 \%)$ & $34(66.7 \%)$ & $51(100 \%)$ \\
\hline & Combined & $31(31.6 \%)$ & $69(68.4)$ & $98(100 \%)$ \\
\hline \multirow{3}{*}{ Age, year (mean \pm s.d.) } & BrainPower & $69.68 \pm 9.52$ & $68.80 \pm 9.60$ & \\
\hline & Placebo & $64.03 \pm 10.73$ & $65.81 \pm 11.41$ & \\
\hline & Combined & $69.07 \pm 9.48$ & $65.22 \pm 11.1$ & $67.07 \pm 10.49$ \\
\hline \multirow{3}{*}{ Age, year (range) } & BrainPower & $52.87-82.80$ & $53.18-84.86$ & \\
\hline & Placebo & $47.28-83.47$ & $49.03-88.43$ & \\
\hline & Combined & $52.87-84.46$ & $47.28-88.43$ & $47.28-88.43$ \\
\hline \multirow{3}{*}{ History of chronic disease, yes/total (\%) } & BrainPower & $39 / 47(83.0 \%)$ & & \\
\hline & Placebo & $31 / 51(60.8 \%)$ & & \\
\hline & Combined & 70/98 (71.4\%) & & \\
\hline \multirow{3}{*}{ History of alcohol use, yes/total (\%) } & BrainPower & $5 / 47(10.6 \%)$ & & \\
\hline & Placebo & 8/51 (15.7\%) & & \\
\hline & Combined & 13/98 (13.3\%) & & \\
\hline \multirow{3}{*}{ History of medication, yes/total (\%) } & BrainPower & $35 / 47(74.5 \%)$ & & \\
\hline & Placebo & 23/51 (45.1\%) & & \\
\hline & Combined & $58 / 98(59.2 \%)$ & & \\
\hline
\end{tabular}

TABLE 3: Mean values of symptom severity of subjective hypomnesis/memory loss (SML) and subjective attention deficit (SAD) (mean \pm s.d.) before and after 12 weeks of BrainPower Advanced and placebo intervention.

\begin{tabular}{lcccc}
\hline Self-reported deficits & Intervention & Before intervention & After intervention & Relative to baseline $(=1)$ \\
\hline \multirow{2}{*}{ Subjective hypomnesis/memory loss (SML) } & BrainPower & $3.77 \pm 0.89$ & $2.94 \pm 0.94$ & 0.779840849 \\
& Placebo & $3.43 \pm 1.19$ & $2.88 \pm 0.77$ & 0.839650146 \\
\hline \multirow{2}{*}{ Subjective concentration/attention deficit (SAD) } & BrainPower & $3.62 \pm 0.99$ & $2.68 \pm 0.89$ & 0.740331492 \\
& Placebo & $3.25 \pm 1.35$ & $2.92 \pm 0.94$ & 0.898461538 \\
\hline
\end{tabular}

history (39/47, 83\%) and medication history (35/47, 74.5\%) compared to the placebo group $\left(31 / 51,60.8 \%, \chi^{2}=5.904\right.$, $P<0.05$ and 23/51, 45.1\%, $\chi^{2}=8.734, P<0.01$, resp.).

3.2. Subjective Memory Complaints (SMC). The mean value, distribution pattern, and the differences between the BrainPower Advanced group and placebo group in the severity level of subjective hypomnesis/forgetfulness/memory loss (SML) and subjective attention/concentration deficit (SAD) before and after the 12-week intervention are shown in Tables 3, 4(a), and 5(a).

The baseline symptom severities of SML and SAD in the BrainPower Advanced group $(3.77 \pm 0.89 ; 3.62 \pm 0.99$, resp.) were about $10 \%$ greater than those of the placebo group $(3.43 \pm 1.19 ; 3.25 \pm 1.35$, resp.) (Table 3$)$. These differences in SML and SAD between the two groups disappeared after the 12-week intervention, primarily due to a greater proportion of the BrainPower Advanced group showing greater reduction of symptom severity than the placebo group (Tables 4(b) and $5(\mathrm{~b})$ ). The placebo group had more participants that showed worsened symptom severity than the BrainPower Advanced group.

Ridit scoring test shows a significant and differential reduction in the SML (mean \pm s.d. $=0.418 \pm 0.236$ versus
$0.575 \pm 0.299, P<0.01$ ) and SAD symptom severity (means $=0.424 \pm 0.229$ versus $0.612 \pm 0.283, P<0.01$ ) after BrainPower Advanced and placebo treatment. Table 4(b) shows that a total of 34 people reported reduced SML symptom severity after BrainPower Advanced intervention (2 people by 3 points, 12 people by 2 points, and 20 people by 1 point), 12 people reported no change, and 1 person reported worsened symptom severity (by 1 point). In comparison, only 23 people reported reduced SML severity after placebo intervention ( 1 person by 3 points, 10 people by 2 points, and 12 people by 1 point), 15 people reported no change in symptom severity, and 13 people reported worsened symptom severity (10 people by 1 point, 2 people by 2 points, and 1 person by 3 points).

Similarly, Table 5(b) shows that a total of 36 people reported different reductions in SAD symptom severity after BrainPower Advanced intervention (2 people by 3 points, 14 people by 2 points, and 20 people by 1 point), 9 people reported no change, and 2 people reported worsened symptom severity (by 1 point) (Table 5(b)). After placebo intervention, 20 people reported different reductions in SAD symptom severity ( 2 people by 3 points, 8 people by 2 points, and 10 people by 1 point), 15 people reported no change, and 16 people reported worsened symptoms (11 people by 1 point, 3 people by 2 points, and 2 people by 3 points). 
TABLE 4: (a) Distribution of symptom severity levels (5-point scale) of subjective hypomnesis/memory loss (SML) in older adults before and after BrainPower Advanced or placebo interventions. (b) Ridit scoring test of the ranked data showed that more subjects showed reduced (-) SML symptoms and far fewer subjects showed worsened SML symptoms (+) after BrainPower Advanced intervention than after placebo intervention, $P<0.01$. (c) McNemar's test of the combined data (2 scales: 1-2 and 3-5) of subjective memory loss (SML) shows that BrainPower Advanced intervention, but not placebo intervention, significantly reversed the proportion of severe SML in the older adults. It was noted, however, that BrainPower Advanced group had more severe cases and fewer mild cases of SML than the placebo group before the intervention.

(a)

\begin{tabular}{lcccccc}
\hline & & \multicolumn{3}{c}{ Distribution of SML symptom severity } & \\
& Group & 1, none or slight & 2, mild & 3, moderate & 4, severe & 5 , very severe \\
\hline \multirow{3}{*}{ Before intervention } & BrainPower group & $0(0 \%)$ & $3(6.4 \%)$ & $16(34.0 \%)$ & $17(36.2 \%)$ & $11(23.4 \%)$ \\
& Placebo group & $5(9.8 \%)$ & $7(13.7 \%)$ & $7(13.7 \%)$ & $25(49.0 \%)$ & $7(13.7 \%)$ \\
& Total & $5(5.1 \%)$ & $10(10.2 \%)$ & $23(23.5 \%)$ & $42(42.9 \%)$ & $18(18.4 \%)$ \\
\hline \multirow{3}{*}{ After intervention } & BrainPower group & $2(4.3 \%)$ & $14(29.8 \%)$ & $18(38.3 \%)$ & $11(23.4 \%)$ & $2(4.3 \%)$ \\
& Placebo group & $2(3.9 \%)$ & $12(23.5 \%)$ & $27(52.9 \%)$ & $10(19.6 \%)$ & $0(0 \%)$ \\
& Total & $4(4.1 \%)$ & $26(26.5 \%)$ & $45(45.9 \%)$ & $21(21.4 \%)$ & $2(2.0 \%)$ \\
\hline
\end{tabular}

(b)

\begin{tabular}{|c|c|c|c|c|c|c|}
\hline \multirow{2}{*}{ Symptom score change } & \multicolumn{2}{|c|}{ BrainPower group } & \multicolumn{2}{|c|}{ Placebo group } & \multicolumn{2}{|c|}{ Total } \\
\hline & $N$ & $\%$ & $N$ & $\%$ & $N$ & $\%$ \\
\hline-3 & 2 & 4.3 & 1 & 2.0 & 3 & 3.1 \\
\hline-2 & 12 & 25.5 & 10 & 19.6 & 22 & 22.4 \\
\hline-1 & 20 & 42.6 & 12 & 23.5 & 32 & 32.7 \\
\hline 0 & 12 & 25.5 & 15 & 29.4 & 27 & 27.6 \\
\hline+1 & 1 & 2.1 & 10 & 19.6 & 11 & 11.2 \\
\hline+2 & 0 & 0.0 & 2 & 3.9 & 2 & 2.0 \\
\hline+3 & 0 & 0.0 & 1 & 2.0 & 1 & 1.0 \\
\hline Total & 47 & 100.0 & 51.0 & 100.0 & 98 & 100.0 \\
\hline
\end{tabular}

(c)

\begin{tabular}{lccccc}
\hline \multirow{2}{*}{ Treatment group } & \multicolumn{2}{c}{ Before intervention } & \multicolumn{2}{c}{ After intervention } & \multirow{2}{*}{$P$ value of McNemar's test } \\
& No or slight & Severe & No or slight & Severe & 0.001 \\
BrainPower group & $3(6.4 \%)$ & $44(93.6 \%)$ & $16(34.0 \%)$ & $31(66.0 \%)$ & 0.791 \\
Placebo group & $12(23.5 \%)$ & $39(76.5 \%)$ & $14(27.5 \%)$ & $37(72.5 \%)$ & \\
Pearson $\chi^{2}$ & 5.547 & & 0.5 & & \\
$P$ & 0.019 & & 0.479 & & \\
\hline
\end{tabular}

Because the symptom severity scores are nominal variables and because only few participants of the BrainPower Advanced group scored 1 and 2 points (Tables 4(a) and 5(a)) of SML and SAD, participants with the severity scores of 1 and 2 were combined as the "slight symptom" group and participants with the severity scores of 3, 4, and 5 were combined as the "severe symptom" group for further chisquare test (Tables $4(\mathrm{c})$ and 5(c)).

It was noted that a greater proportion of the BrainPower Advanced group $(44 / 47,93.6 \%)$ than the placebo group (39/51, 76.5\%) had severe SML symptoms (severity scores $\geqslant 3$ ), or a smaller proportion of the BrainPower Advanced group had slight SML symptoms (severity scores $\leqslant 2)(3 / 47$, $6.4 \%)$ than the placebo group $(12 / 51,23.5 \%)$ (Pearson $\chi^{2}=$ 5.547, $P=0.019$ ) before the start of the intervention (Tables 4(a) and 4(c)). Similar pretreatment differences in severe SAD distribution existed between the BrainPower Advanced (43/47, 91.5\%) and placebo groups (37/51, 72.5\%) (severity scores $\geqslant 3$ ) (Pearson $\left.\chi^{2}=5.852, P=0.016\right)$ (Tables 5(a) and $5(\mathrm{c})$ ).

After the intervention, however, the BrainPower Advanced group had fewer cases of severe SML (31) and SAD (28) than the placebo group (37 for SML and 32 for $\mathrm{SAD}$, resp.) and the difference in SML and SAD between the BrainPower Advanced and placebo groups was no longer significant (Pearson $\chi^{2}=0.5, P=0.479 ; \chi^{2}=0.104$, $P=0.748$, resp.) (Tables 4(c) and 5(c)).

Placebo group analysis of the combined data showed that the proportion of people with severe SML showed little change after placebo intervention (reduced by 2 people, from 39 to $37, P>0.05$ ) whereas the proportion of people with severe SML dropped significantly after BrainPower Advanced intervention (reduced by 13 people, from 44 to 31, $P<0.001$ ) (Table 4(c)). Similarly, the proportion of severe SAD did not change significantly after placebo intervention (reduced by 5 people, from 37 to $32, P>0.05$ ) whereas 
TABLE 5: (a) Distribution of subjective attention deficit (SAD) symptom severity (using a 5-point questionnaire) in older adults before and after BrainPower Advanced or placebo intervention. (b) Ridit scoring test of the ranked data showed that more people in the BrainPower Advanced group showed reduced SAD (-) and fewer people in the BrainPower Advanced group showed no change or worsened SAD than people in the placebo group after the interventions $(P<0.01)$. (c) McNemar's test of the combined data ( 2 scales) of subjective attention deficit (SAD) shows that BrainPower Advanced intervention, but not placebo intervention, reversed a significantly greater proportion of severe $\mathrm{SAD}$ in the older adults. It was noted, however, that BrainPower Advanced group had more severe cases and fewer mild cases of SAD than the placebo group before the intervention.

(a)

\begin{tabular}{|c|c|c|c|c|c|c|}
\hline & \multicolumn{6}{|c|}{ Distribution of SAD symptom severity } \\
\hline & Group & 1 , none or slight & 2, mild & 3 , moderate & 4 , severe & 5 , very severe \\
\hline \multirow{3}{*}{ Before intervention } & BrainPower group & $1(2.1 \%)$ & $3(6.4 \%)$ & $16(34.0 \%)$ & $19(40.4 \%)$ & $8(17.0 \%)$ \\
\hline & Placebo group & $7(13.7 \%)$ & $7(13.7 \%)$ & $8(15.7 \%)$ & $22(43.1 \%)$ & $7(13.7 \%)$ \\
\hline & Total & $8(8.2 \%)$ & $10(10.2 \%)$ & $24(24.5 \%)$ & $41(41.8 \%)$ & $15(15.3 \%)$ \\
\hline \multirow{3}{*}{ After intervention } & BrainPower group & $4(8.5 \%)$ & $15(31.9 \%)$ & $21(44.7 \%)$ & $6(12.8 \%)$ & $1(2.1 \%)$ \\
\hline & Placebo group & $2(3.9 \%)$ & $17(33.3 \%)$ & $16(31.4 \%)$ & $15(29.4 \%)$ & $1(2.0 \%)$ \\
\hline & Total & $6(6.1 \%)$ & $32(32.7 \%)$ & $37(37.8 \%)$ & $21(21.4 \%)$ & $2(2.0 \%)$ \\
\hline
\end{tabular}

(b)

\begin{tabular}{|c|c|c|c|c|c|c|}
\hline \multirow{2}{*}{ Symptom score change } & \multicolumn{2}{|c|}{ BrainPower group } & \multicolumn{2}{|c|}{ Placebo group } & \multicolumn{2}{|c|}{ Total } \\
\hline & $N$ & $\%$ & $N$ & $\%$ & $N$ & $\%$ \\
\hline-3 & 2 & 4.3 & 2 & 3.9 & 4 & 4.1 \\
\hline-2 & 14 & 29.8 & 8 & 15.7 & 22 & 22.4 \\
\hline-1 & 20 & 42.6 & 10 & 19.6 & 30 & 30.6 \\
\hline 0 & 9 & 19.1 & 15 & 29.4 & 14 & 14.3 \\
\hline+1 & 2 & 4.3 & 11 & 21.6 & 13 & 13.3 \\
\hline+2 & 0 & 0.0 & 3 & 5.9 & 3 & 3.1 \\
\hline+3 & 0 & 0.0 & 2 & 3.9 & 2 & 2.0 \\
\hline Total & 47 & 100.0 & 51 & 100.0 & 98 & 100.0 \\
\hline
\end{tabular}

(c)

\begin{tabular}{lccccc}
\hline \multirow{2}{*}{ Treatment group } & \multicolumn{2}{c}{ Before intervention } & \multicolumn{2}{c}{ After intervention } & \multirow{2}{*}{$P$ value of McNemar's test } \\
& No or slight & Severe & No or slight & Severe & 0.001 \\
BrainPower group & $4(8.5 \%)$ & $43(91.5 \%)$ & $19(40.4 \%)$ & $28(59.6 \%)$ & 0.302 \\
Placebo group & $14(27.5 \%)$ & $37(72.5 \%)$ & $19(37.3 \%)$ & $32(62.7 \%)$ & \\
Pearson $\chi^{2}$ & 5.852 & & 0.104 & & \\
$P$ & 0.016 & & 0.748 & & \\
\hline
\end{tabular}

the proportion of severe SAD decreased significantly after BrainPower Advanced intervention (reduced by 15 people, from 43 to $28, P<0.001$ ) (Table 5(c)).

3.3. Memory Function Test Scores. The memory function test focused on 3 subareas: visual/auditory impression memory, abstract thinking, and immediate memory recall. The subtest scores and the combined total test scores are shown in Tables 6(a) and 6(b), respectively. The BrainPower Advanced group had about $10 \%$ lower baseline scores than placebo group in audio/visual memory ( $2.28 \pm 1.06$ versus $2.51 \pm 0.81)$, abstract thinking $(2.40 \pm 1.08$ versus $2.73 \pm 1.08)$, and combined total memory function scores $(6.85 \pm 2.46$ versus $7.37 \pm$ $2.32)$, but similar scores in memory retrieval $(2.17 \pm 1.15$ versus $2.18 \pm 1.14)$. These baseline differences disappeared after the 12 -week intervention $(3.43 \pm 0.83$ versus $3.41 \pm$
$1.00,3.45 \pm 0.75$ versus $3.47 \pm 0.92,9.66 \pm 1.85$ versus $9.39 \pm 1.98$, and $2.81 \pm 0.92$ versus $2.47 \pm 0.83$, resp.). Both the BrainPower Advanced and the placebo groups produced significant improvements $(129 \%-150 \%)(P<0.01$, each) of the subtests and combined total scores in the older adults, with the BrainPower Advanced group producing better improvements (1.50-, 1.35-, 1.43-, and 1.29-fold relative to the baseline values of audio/visual memory, abstract thinking, memory retrieval, and combined total function test scores) than the placebo group (1.35-, 1.27-, 1.13-, and 1.27-fold, resp.) (Tables 6(a) and 6(b)).

Ridit scoring test showed that the improvement in the combined total scores of the memory function subtests was significantly better after the BrainPower Advanced intervention (mean $=0.56 \pm 0.287)$ than after the placebo intervention $(0.445 \pm 0.276)(P<0.05)$ (Table 6(c)). 
TABLE 6: (a) Subtest scores (mean \pm s.d.) of memory function test before and after the interventions between BrainPower Advanced and placebo groups. (b) Comparison of the combined total memory function test scores between BrainPower Advanced and placebo groups shows no differences between the two groups before or after the interventions. However, BrainPower Advanced and placebo interventions both improved the combined total scores significantly $(P<0.01$ each). (c) Different impacts of BrainPower Advanced and placebo interventions on the improvement of memory function tests. Ridit scoring test of the ranked data showed a better improvement after BrainPower Advanced intervention than after placebo interventions $(P<0.05)$.

(a)

\begin{tabular}{|c|c|c|c|c|c|c|}
\hline $\begin{array}{l}\text { Memory function } \\
\text { subtest scores }\end{array}$ & & Before intervention & After intervention & $\begin{array}{l}\text { Improvement } \\
\text { relative } \\
\text { to baseline }(=1)\end{array}$ & $t$ & $P$ \\
\hline \multirow{4}{*}{$\begin{array}{l}\text { Audio/visual } \\
\text { memory }\end{array}$} & BrainPower & $2.28 \pm 1.06$ & $3.43 \pm 0.83$ & 1.50 & -8.247 & $<0.001$ \\
\hline & Placebo & $2.51 \pm 0.81$ & $3.41 \pm 1.00$ & 1.36 & -5.014 & $<0.001$ \\
\hline & $t$ & -1.232 & 0.074 & & & \\
\hline & $P$ & 0.221 & 0.941 & & & \\
\hline \multirow{4}{*}{ Abstracting ability } & BrainPower & $2.40 \pm 1.08$ & $3.45 \pm 0.75$ & 1.44 & -6.602 & $<0.001$ \\
\hline & Placebo & $2.73 \pm 1.08$ & $3.47 \pm 0.92$ & 1.27 & -4.791 & $<0.001$ \\
\hline & $t$ & -1.474 & 0.081 & & & \\
\hline & $P$ & 0.144 & 0.889 & & & \\
\hline \multirow{4}{*}{ Memory retrieval } & BrainPower & $2.17 \pm 1.15$ & $2.81 \pm 0.92$ & 1.29 & -3.526 & 0.001 \\
\hline & Placebo & $2.18 \pm 1.14$ & $2.47 \pm 0.83$ & 1.13 & -1.820 & 0.075 \\
\hline & $t$ & -.027 & 0.410 & & & \\
\hline & $P$ & 0.979 & 0.060 & & & \\
\hline
\end{tabular}

(b)

\begin{tabular}{lccr}
\hline & Before intervention & After intervention & $t$ \\
\hline BrainPower & $6.85 \pm 2.46$ & $9.66 \pm 1.85$ & 8.478 \\
Placebo & $7.37 \pm 2.32$ & $9.39 \pm 1.98$ & 6.988 \\
$t$ & -1.08 & 0.692 & $<0.001$ \\
$P$ & 0.283 & 0.491 & \\
\hline
\end{tabular}

(c)

\begin{tabular}{|c|c|c|c|c|c|c|}
\hline \multirow{2}{*}{ Score change } & \multicolumn{2}{|c|}{ BrainPower intervention } & \multicolumn{2}{|c|}{ Placebo control } & \multicolumn{2}{|c|}{ Total } \\
\hline & $N$ & $\%$ & $N$ & $\%$ & $N$ & $\%$ \\
\hline-5 & 1 & 2.1 & 0 & 0 & 1 & 1 \\
\hline-3 & 0 & 0 & 1 & 2 & 1 & 1 \\
\hline-2 & 1 & 2.1 & 2 & 3.9 & 3 & 3.1 \\
\hline-1 & 1 & 2.1 & 5 & 9.8 & 6 & 6.1 \\
\hline 0 & 2 & 4.3 & 2 & 3.9 & 4 & 4.1 \\
\hline+1 & 6 & 12.8 & 5 & 9.8 & 11 & 11.2 \\
\hline+2 & 7 & 14.9 & 17 & 33.3 & 24 & 24.5 \\
\hline+3 & 12 & 25.5 & 8 & 15.7 & 20 & 20.4 \\
\hline+4 & 9 & 19.1 & 5 & 9.8 & 14 & 14.3 \\
\hline+5 & 2 & 4.3 & 5 & 9.8 & 7 & 7.1 \\
\hline+6 & 4 & 8.5 & 0 & 0 & 4 & 4.1 \\
\hline+7 & 2 & 4.3 & 1 & 2 & 3 & 3.1 \\
\hline Total & 47 & 100.0 & 51 & 100.0 & 98 & 100.0 \\
\hline
\end{tabular}

\section{Discussion}

In this exploratory randomized, double-blind, placebocontrolled study, we evaluated the effectiveness of a proprietary dietary supplement, BrainPower Advanced, in older adults with SMCs. The results show that BrainPower
Advanced intervention for 12 weeks was safe and effective in improving the symptoms of SMC in older adults.

SMCs are defined as self-awareness of memory loss that can be assessed by a simple "yes" or "no" questionnaire but are often not detected by clinicians using objective memory scales [2]. SMC is also a predictor of mild cognitive 
impairment (MCI) and of future cognitive decline [156, 157]. There are studies showing that people with SMC are 3-6 times more likely to develop MCI than people without SMC [158$162]$.

Because SMCs are often reversible, improvement of SMC would represent a good opportunity to intervene prodromal MCI and cognitive decline. So far, no proven agents are available for SMC. BrainPower Advanced is a dietary supplement based on polyherbal extracts, nutrients, and vitamins. Previous studies have shown that the active ingredients of BrainPower Advanced could potentially improve cognitive function in different age groups of healthy people in the presence or absence of SMCs through various mechanisms including anti-inflammation, improved cerebral blood flow and perfusion, and improved glucose/energy metabolism (Table 1).

In the present study, BrainPower Advanced treatment reversed 13 of the $44(29.5 \%)$ cases of severe SML and 15 of the $43(34.9 \%)$ cases of severe SAD. In contrast, placebo treatment reversed only 2 of the 39 (5.1\%) cases of severe SML $(P>0.05)$ and 5 of the $37(13.5 \%)$ cases of severe SAD $(P>$ $0.05)$. Furthermore, a greater proportion of the participants showed various degrees of symptom improvement after BrainPower Advanced intervention (72.3\%, 34/47 for SML and $76.6 \%, 36 / 47$ for SAD) than after placebo treatment (49\%, 25/51 for SML and 39.2\%, 20/51 for SAD).

In contrast, a greater proportion of participants in the placebo group reported worsened symptoms of SML (25.5\%, $13 / 51)$ and SAD $(31.4 \%, 16 / 51)$ or no change in SML $(29.4 \%$, $15 / 51)$ and $\operatorname{SAD}(29.4 \%, 15 / 51)$ compared to the BrainPower Advanced group that reported worsened SML $(2.1 \%, 1 / 47)$ and SAD $(2 \%, 2 / 47)$ or no change in SML $(25.5 \%, 12 / 47)$ and SAD $(19.1 \%, 9 / 47)$ after the intervention.

The $29.5 \%$ reversion rate $(13 / 44)$ of severe SML and $34.9 \%$ reversion rate (15/43) of severe SAD by BrainPower Advanced are comparable to the reported $15 \%-35 \%$ response rate of MCI to AChEIs treatment and the $30 \%$ response rate of MCI to NMDA receptor antagonist treatment [139]. Given that there is no standard anti-SMC treatment yet, the current results are very promising [140-142].

These results suggest that BrainPower Advanced is not only effective in reducing a significant portion (about 30\%) of severe SMC and in reducing symptom severity in about $70 \%$ of the subjects with SMCs, but also effective in reducing the progression or worsening of SMCs. It is noted, however, that $25.5 \%$ of the people with severe SML showed no response to BrainPower Advanced intervention.

In this study, no significant differences were found in visual/auditory memory, abstract thinking, and memory retrieval and in the combined total memory function testing scores between the BrainPower Advanced and placebo groups before or after the intervention. Both BrainPower Advanced and placebo interventions resulted in significantly improved memory function performance, albeit with the BrainPower Advanced group showing better improvement than the placebo group at a nonsignificant level.

Because both placebo and BrainPower Advanced intervention enhanced the performance scores of the memory function tests, this raised the possibility that factors other than the intervention per se may be responsible for the improvement. One such possibility is that the postintervention memory test score was unintendedly "enhanced" by the preintervention test. Like any learning activity, practice or repetition of the same learning task would improve performance and produce better scores. This may not mean that the memory was "getting better" but simply reflecting the remembered answers from the last test. There are suggestions that the same memory tests should not be given within a short period of time (3-6 months) or that only the tests taken the first time should be taken seriously as a true measure of memory abilities.

It is the current view that SMC is a subjective experience that cannot be reliably measured by objective memory scales due to the subtle and heterogeneous nature of SMC [2-5]. Nevertheless, more accurate diagnosis of SMC and/or MCI could be corroborated by informants and by using different questionnaires and memory scales before and after an intervention such as the use of Mini-Mental State Examination (MMSE), Six-Item Screener, Subjective Memory Rating Scale (SMRS) and Deterioration Cognitive Observee (DECO) [143], Memory Complaint Questionnaire (MAC-Q), and Subjective Cognitive Decline Questionnaire (SCD-Q) [144]. The updated Wechsler Memory Scale (WMS) also has a battery of subtests for evaluating multiple aspects of learning and memory including immediate and delayed memory for visual working memory and auditory memory [145-148].

There are other limitations of this study. The sample size is too small to detect potential performance differences in the memory function tests. Despite the randomization process, more participants in the BrainPower Advanced group had a history of disease and medication use than the placebo group. Due to the multi-ingredient nature of BrainPower Advanced, it was difficult to determine whether any single ingredient (Ginkgo biloba, Camellia sinensis, vinpocetine, kola nut, hup A, PS, L-tyrosine, L-pyroglutamic acid, acetyl-L-carnitine, choline bitartrate, L-glutamine, L-phenylalanine, L-cysteine, vitamin B6, or vitamin B12) was primarily responsible for BrainPower Advanced overall effects or, more likely, whether it was a synergistic combination of the ingredients working together that produced the observed results. Because SMCs are heterogeneous and potentially affected by a range of genetic and epigenetic factors including lifestyle [149], daily activity/exercise [150, 151], APOE genotype [163], affective status [164-166], education achievements [11, 167], inflammation, and alcohol use, controlling these factors would allow better understanding of BrainPower Advanced intervention in further studies [168].

\section{Conclusion}

Twelve-week BrainPower Advanced intervention was effective and safe in reducing the progression of symptom severity in older adults with severe SML and SAD. As no proven agents are currently available in reversing or delaying the progression of SMC in the increasing aging population, further well-controlled, large-scale studies could validate if long-term dietary supplementation of combined polyherbal 
ingredients, nutrients, and vitamins could be an alternative prophylactic strategy for older adults with SMCs.

\section{Disclosure}

The sponsor had no role in the design or analysis of this study or the interpretation of the findings. Mina Shariff and Tuong Nguyen are employees of DRM Resources.

\section{Competing Interests}

Jingfen Zhu, Guoqiang Xing, Su Chen, Lihua Dai, Tian Shen, Yi Feng, Yeats Ye, Jianyu Rao, and Rong Shi have declared that they have no competing or potential conflict of interests in the study.

\section{Authors' Contributions}

Jingfen Zhu, Guoqiang Xing, and Su Chen have contributed equally to this work. All authors have read the paper and had full access to the study data.

\section{Acknowledgments}

The authors thank Reza Emaddudin for proofreading the paper. This study was sponsored by DRM Resources (Costa Mesa, California, USA).

\section{References}

[1] T. Hänninen, K. Koivisto, K. J. Reinikainen et al., "Prevalence of ageing-associated cognitive decline in an elderly population," Age and Ageing, vol. 25, no. 3, pp. 201-205, 1996.

[2] K. Abdulrab and R. Heun, "Subjective memory impairment. A review of its definitions indicates the need for a comprehensive set of standardised and validated criteria," European Psychiatry, vol. 23, no. 5, pp. 321-330, 2008.

[3] A. Pearman and M. Storandt, "Self-discipline and selfconsciousness predict subjective memory in older adults," Journals of Gerontology B Psychological Sciences and Social Sciences, vol. 60, no. 3, pp. P153-P157, 2005.

[4] B. E. Snitz, L. A. Morrow, E. G. Rodriguez, K. A. Huber, and J. A. Saxton, "Subjective memory complaints and concurrent memory performance in older patients of primary care providers," Journal of the International Neuropsychological Society, vol. 14, no. 6, pp. 1004-1013, 2008.

[5] B. E. Snitz, L. Yu, P. K. Crane, C.-C. H. Chang, T. F. Hughes, and M. Ganguli, "Subjective cognitive complaints of older adults at the population level: an item response theory analysis," Alzheimer Disease and Associated Disorders, vol. 26, no. 4, pp. 344-351, 2012.

[6] A. Burns and M. Zaudig, "Mild cognitive impairment in older people," The Lancet, vol. 360, no. 9349, pp. 1963-1965, 2002.

[7] R. O. Roberts, D. S. Knopman, Y. E. Geda, R. H. Cha, V. L. Roger, and R. C. Petersen, "Coronary heart disease is associated with non-amnestic mild cognitive impairment," Neurobiology of Aging, vol. 31, no. 11, pp. 1894-1902, 2010.

[8] R. Grambaite, E. Hessen, E. Auning, D. Aarsland, P. Selnes, and T. Fladby, "Correlates of subjective and mild cognitive impairment: depressive symptoms and CSF biomarkers," Dementia and Geriatric Cognitive Disorders Extra, vol. 3, pp. 291-300, 2013.

[9] M. M. Mielke, R. Savica, H. J. Wiste et al., "Head trauma and in vivo measures of amyloid and neurodegeneration in a population-based study," Neurology, vol. 82, no. 1, pp. 70-76, 2014.

[10] A. Sajjad, S. S. Mirza, M. L. P. Portegies et al., "Subjective memory complaints and the risk of stroke," Stroke, vol. 46, no. 1, pp. 170-175, 2015.

[11] A. Alagoa João, J. Maroco, S. Ginó, T. Mendes, A. de Mendonça, and I. P. Martins, "Education modifies the type of subjective memory complaints in older people," International Journal of Geriatric Psychiatry, vol. 31, no. 2, pp. 153-160, 2016.

[12] S. F. Rowell, J. S. Green, B. A. Teachman, and T. A. Salthouse, "Age does not matter: memory complaints are related to negative affect throughout adulthood," Aging \& Mental Health, 2015.

[13] R. C. Petersen, “Early diagnosis of Alzheimer's disease: is MCI too late?" Current Alzheimer Research, vol. 6, no. 4, pp. 324-330, 2009.

[14] J. Bischkopf, A. Busse, and M. C. Angermeyer, "Mild cognitive impairment-a review of prevalence, incidence and outcome according to current approaches," Acta Psychiatrica Scandinavica, vol. 106, no. 6, pp. 403-414, 2002.

[15] A. Busse, J. Bischkopf, S. G. Riedel-Heller, and M. C. Angermeyer, "Subclassifications for mild cognitive impairment: prevalence and predictive validity," Psychological Medicine, vol. 33, no. 6, pp. 1029-1038, 2003.

[16] F. Panza, C. Capurso, A. D’Introno, A. M. Colacicco, A. Capurso, and V. Solfrizzi, "Prevalence rates of mild cognitive impairment subtypes and progression to dementia," Journal of the American Geriatrics Society, vol. 54, no. 9, pp. 1474-1475, 2006.

[17] F. Panza, C. Capurso, A. D’Introno, A. M. Colacicco, A. Capurso, and V. Solfrizzi, "Mild cognitive impairment: risk of Alzheimer disease and rate of cognitive decline," Neurology, vol. 68, no. 12, pp. 964-965, 2007.

[18] S. Gauthier, B. Reisberg, M. Zaudig et al., "Mild cognitive impairment," The Lancet, vol. 367, no. 9518, pp. 1262-1270, 2006.

[19] K. Meguro, K. Akanuma, M. Meguro, S. Yamaguchi, H. Ishii, and M. Tashiro, "Prevalence and prognosis of prodromal Alzheimer's disease as assessed by magnetic resonance imaging and f-fluorodeoxyglucose-positron emission tomography in a community: reanalysis from the Osaki-Tajiri project," Psychogeriatrics, 2015.

[20] S. J. B. Vos, F. Verhey, L. Frölich et al., "Prevalence and prognosis of alzheimer's disease at the mild cognitive impairment stage," Brain, vol. 138, no. 5, pp. 1327-1338, 2015.

[21] A. Ward, S. Tardiff, C. Dye, and H. M. Arrighi, "Rate of conversion from prodromal Alzheimer's disease to Alzheimer's dementia: a systematic review of the literature," Dementia and Geriatric Cognitive Disorders Extra, vol. 3, no. 1, pp. 320-332, 2013.

[22] D. G. Darby, A. Brodtmann, R. H. Pietrzak et al., "Episodic memory decline predicts cortical amyloid status in communitydwelling older adults," Journal of Alzheimer's Disease, vol. 27, no. 3, pp. 627-637, 2011.

[23] S. Erk, A. Spottke, A. Meisen, M. Wagner, H. Walter, and F. Jessen, "Evidence of neuronal compensation during episodic memory in subjective memory impairment," Archives of General Psychiatry, vol. 68, no. 8, pp. 845-852, 2011. 
[24] K. A. Gifford, D. Liu, S. M. Damon et al., "Subjective memory complaint only relates to verbal episodic memory performance in mild cognitive impairment," Journal of Alzheimer's Disease, vol. 44, no. 1, pp. 309-318, 2015.

[25] A. Forsberg, H. Engler, O. Almkvist et al., "PET imaging of amyloid deposition in patients with mild cognitive impairment," Neurobiology of Aging, vol. 29, no. 10, pp. 1456-1465, 2008.

[26] B. E. Snitz, L. A. Weissfeld, A. D. Cohen et al., "Subjective cognitive complaints, personality and brain amyloid-beta in cognitively normal older adults," The American Journal of Geriatric Psychiatry, vol. 23, no. 9, pp. 985-993, 2015.

[27] Y. Y. Lim, K. A. Ellis, K. Harrington et al., "Cognitive decline in adults with amnestic mild cognitive impairment and high amyloid- $\beta$ : prodromal Alzheimer's disease?" Journal of Alzheimer's Disease, vol. 33, no. 4, pp. 1167-1176, 2013.

[28] S. M. Landau, M. A. Mintun, A. D. Joshi et al., "Amyloid deposition, hypometabolism, and longitudinal cognitive decline," Annals of Neurology, vol. 72, no. 4, pp. 578-586, 2012.

[29] E. E. Smith and S. M. Greenberg, “ $\beta$-Amyloid, blood vessels, and brain function," Stroke, vol. 40, no. 7, pp. 2601-2606, 2009.

[30] S. Karim, S. Hopkins, N. Purandare et al., "Peripheral inflammatory markers in amnestic mild cognitive impairment," International Journal of Geriatric Psychiatry, vol. 29, no. 3, pp. 221-226, 2014.

[31] M. L. Bader Lange, G. Cenini, M. Piroddi et al., "Loss of phospholipid asymmetry and elevated brain apoptotic protein levels in subjects with amnestic mild cognitive impairment and Alzheimer disease," Neurobiology of Disease, vol. 29, no. 3, pp. 456-464, 2008.

[32] D. Hadjiev, "Asymptomatic ischemic cerebrovascular disorders and neuroprotection with vinpocetine," Ideggyogyaszati Szemle, vol. 56, no. 5-6, pp. 166-172, 2003.

[33] G. Douaud, R. A. L. Menke, A. Gass et al., "Brain microstructure reveals early abnormalities more than two years prior to clinical progression from mild cognitive impairment to Alzheimer's disease," Journal of Neuroscience, vol. 33, no. 5, pp. 2147-2155, 2013.

[34] S. L. Leal and M. A. Yassa, "Perturbations of neural circuitry in aging, mild cognitive impairment, and Alzheimer's disease," Ageing Research Reviews, vol. 12, no. 3, pp. 823-831, 2013.

[35] L. Zhuang, P. S. Sachdev, J. N. Trollor et al., "Microstructural white matter changes, not hippocampal atrophy, detect early amnestic mild cognitive impairment," PLoS ONE, vol. 8, no. 3, Article ID e58887, 2013.

[36] R. Cabeza, C. L. Grady, L. Nyberg et al., "Age-related differences in neural activity during memory encoding and retrieval: a positron emission tomography study," The Journal of Neuroscience, vol. 17, no. 1, pp. 391-400, 1997.

[37] D. A. Loewenstein, A. Acevedo, E. Potter et al., "Severity of medial temporal atrophy and amnestic mild cognitive impairment: selecting type and number of memory tests," The American Journal of Geriatric Psychiatry, vol. 17, no. 12, pp. 10501058, 2009.

[38] M. Okamoto, Y. Wada, Y. Yamaguchi et al., "Process-specific prefrontal contributions to episodic encoding and retrieval of tastes: a functional NIRS study," NeuroImage, vol. 54, no. 2, pp. 1578-1588, 2011.

[39] G. Prendergast, E. Limbrick-Oldfield, E. Ingamells, S. Gathercole, A. Baddeley, and G. G. R. Green, "Differential patterns of prefrontal MEG activation during verbal \& visual encoding and retrieval," PLoS ONE, vol. 8, no. 12, Article ID e82936, 2013.
[40] R. Manenti, M. Cotelli, and C. Miniussi, "Successful physiological aging and episodic memory: a brain stimulation study," Behavioural Brain Research, vol. 216, no. 1, pp. 153-158, 2011.

[41] B. P. Lockhart and P. J. Lestage, "Cognition enhancing or neuroprotective compounds for the treatment of cognitive disorders: why? when? which?" Experimental Gerontology, vol. 38, no. 1-2, pp. 119-128, 2003.

[42] M. A. Taffe, M. R. Weed, T. Gutierrez, S. A. Davis, and L. H. Gold, "Differential muscarinic and NMDA contributions to visuo-spatial paired-associate learning in rhesus monkeys," Psychopharmacology, vol. 160, no. 3, pp. 253-262, 2002.

[43] E. L. Schaeffer and W. F. Gattaz, "Cholinergic and glutamatergic alterations beginning at the early stages of Alzheimer disease: participation of the phospholipase $\mathrm{A}_{2}$ enzyme," Psychopharmacology, vol. 198, no. 1, pp. 1-27, 2008.

[44] G. L. Wenk, "Neuropathologic changes in Alzheimer's disease: potential targets for treatment," Journal of Clinical Psychiatry, vol. 67, supplement 3, pp. 3-7, 2006.

[45] P. T. Francis, "Glutamatergic systems in Alzheimer's disease," International Journal of Geriatric Psychiatry, vol. 18, no. 1, pp. S15-S21, 2003.

[46] C. McVeigh and P. Passmore, "Vascular dementia: prevention and treatment," Clinical Interventions in Aging, vol. 1, no. 3, pp. 229-235, 2006.

[47] K. M. Cosman, L. L. Boyle, and A. P. Porsteinsson, "Memantine in the treatment of mild-to-moderate Alzheimer's disease," Expert Opinion on Pharmacotherapy, vol. 8, no. 2, pp. 203-214, 2007.

[48] O. Peters, D. Lorenz, A. Fesche et al., "A combination of galantamine and memantine modifies cognitive function in subjects with amnestic MCI," Journal of Nutrition, Health and Aging, vol. 16, no. 6, pp. 544-548, 2012.

[49] S. Salloway, S. Correia, and S. Richardson, "Key lessons learned from short-term treatment trials of cholinesterase inhibitors for amnestic MCI," International Psychogeriatrics, vol. 20, no. 1, pp. 40-46, 2008.

[50] R. C. Petersen, R. G. Thomas, M. Grundman et al., "Vitamin E and donepezil for the treatment of mild cognitive impairment," The New England Journal of Medicine, vol. 352, no. 23, pp. 23792388, 2005.

[51] H. H. Feldman, S. Ferris, B. Winblad et al., "Effect of rivastigmine on delay to diagnosis of Alzheimer's disease from mild cognitive impairment: the InDDEx study," The Lancet Neurology, vol. 6, no. 6, pp. 501-512, 2007.

[52] J. T. O’Brien, A. Burns, and Group BAPDC, "Clinical practice with anti-dementia drugs: a revised (second) consensus statement from the British Association for Psychopharmacology," Journal of Psychopharmacology, vol. 25, no. 8, pp. 997-1019, 2011.

[53] T. C. Russ, "Cholinesterase inhibitors should not be prescribed for mild cognitive impairment," Evidence-Based Medicine, vol. 19, no. 3, article 101, 2014.

[54] T. C. Russ and J. R. Morling, "Cholinesterase inhibitors for mild cognitive impairment," Cochrane Database of Systematic Reviews, vol. 9, Article ID CD009132, 2012.

[55] A. Servello, P. Andreozzi, F. Bechini et al., "Effect of ache and $\mathrm{BuChE}$ inhibition by rivastigmin in a group of old-old elderly patients with cerebrovascular impairment (SIVD type)," Minerva Medica, vol. 105, no. 2, pp. 167-174, 2014.

[56] R. M. Lane and T. Darreh-Shori, "Understanding the beneficial and detrimental effects of donepezil and rivastigmine to improve their therapeutic value," Journal of Alzheimer's Disease, vol. 44, no. 4, pp. 1039-1039, 2015. 
[57] P. R. Heckman, C. Wouters, and J. Prickaerts, "Phosphodiesterase inhibitors as a target for cognition enhancement in aging and Alzheimer's disease: a translational overview," Current Pharmaceutical Design, vol. 21, no. 3, pp. 317-331, 2014.

[58] M. Singer, B. Romero, E. Koenig, H. Förstl, and H. Brunner, "Nightmares in patients with Alzheimer's disease caused by donepezil. Therapeutic effect depends on the time of intake," Nervenarzt, vol. 76, no. 9, pp. 1128-1129, 2005.

[59] N. Mimica and P. Presečki, "Side effects of approved antidementives," Psychiatria Danubina, vol. 21, no. 1, pp. 108-113, 2009.

[60] P. Gareri, D. Putignano, A. Castagna et al., "Retrospective study on the benefits of combined memantine and cholinesterase inhibitor treatment in aged patients affected with Alzheimer's disease: the memage study," Journal of Alzheimer's Disease, vol. 41, no. 2, pp. 633-640, 2014.

[61] M. D. Nguyen and R. L. Salbu, "Donepezil 23 mg: a brief insight on efficacy and safety concerns," Consultant Pharmacist, vol. 28, no. 12, pp. 800-803, 2013.

[62] P. Anand and B. Singh, "A review on cholinesterase inhibitors for Alzheimer's disease," Archives of Pharmacal Research, vol. 36, no. 4, pp. 375-399, 2013.

[63] S. G. Di Santo, F. Prinelli, F. Adorni, C. Caltagirone, and M. Musicco, "A meta-analysis of the efficacy of donepezil, rivastigmine, galantamine, and memantine in relation to severity of Alzheimer's disease," Journal of Alzheimer's Disease, vol. 35, no. 2, pp. 349-361, 2013.

[64] S. Mehta, K. Chandersekhar, G. Prasadrao et al., "Safety and efficacy of donepezil hydrochloride in patients with mild to moderate Alzheimer's disease: findings of an observational study," Indian Journal of Psychiatry, vol. 54, no. 4, pp. 337-343, 2012.

[65] P. Russo, A. Frustaci, A. Del Bufalo, M. Fini, and A. Cesario, "Multitarget drugs of plants origin acting on Alzheimer's disease," Current Medicinal Chemistry, vol. 20, no. 13, pp. 16861693, 2013.

[66] G. Pepeu, I. M. Pepeu, and L. Amaducci, "A review of phosphatidylserine pharmacological and clinical effects. Is phosphatidylserine a drug for the ageing brain?" Pharmacological Research, vol. 33, no. 2, pp. 73-80, 1996.

[67] H.-Y. Kim, B. X. Huang, and A. A. Spector, "Phosphatidylserine in the brain: metabolism and function," Progress in Lipid Research, vol. 56, no. 1, pp. 1-18, 2014.

[68] M. A. Starks, S. L. Starks, M. Kingsley, M. Purpura, and R. Jäger, "The effects of phosphatidylserine on endocrine response to moderate intensity exercise," Journal of the International Society of Sports Nutrition, vol. 5, article 11, 2008.

[69] P. V. Escribá, X. Busquets, J. Inokuchi et al., "Membrane lipid therapy: modulation of the cell membrane composition and structure as a molecular base for drug discovery and new disease treatment," Progress in Lipid Research, vol. 59, pp. 38-53, 2015.

[70] T. Crook, W. Petrie, C. Wells, and D. C. Massari, "Effects of phosphatidylserine in Alzheimer's disease," Psychopharmacology Bulletin, vol. 28, no. 1, pp. 61-66, 1992.

[71] T. H. Crook, J. Tinklenberg, J. Yesavage et al., "Effects of phosphatidylserine in age-associated memory impairment," Neurology, vol. 41, no. 5, pp. 644-649, 1991.

[72] S. Schreiber, "An open trial of plant-source derived phosphatydilserine for treatment of age-related cognitive decline," Israel Journal of Psychiatry and Related Sciences, vol. 37, no. 4, pp. 302$307,2000$.
[73] A. Kato-Kataoka, M. Sakai, R. Ebina, C. Nonaka, T. Asano, and T. Miyamori, "Soybean-derived phosphatidylserine improves memory function of the elderly Japanese subjects with memory complaints," Journal of Clinical Biochemistry and Nutrition, vol. 47, no. 3, pp. 246-255, 2010.

[74] K. Yurko-Mauro, "Cognitive and cardiovascular benefits of docosahexaenoic acid in aging and cognitive decline," Current Alzheimer Research, vol. 7, no. 3, pp. 190-196, 2010.

[75] Y. Richter, Y. Herzog, Y. Lifshitz, R. Hayun, and S. Zchut, "The effect of soybean-derived phosphatidylserine on cognitive performance in elderly with subjective memory complaints: a pilot study," Clinical Interventions in Aging, vol. 8, pp. 557-563, 2013.

[76] H.-J. Park, S. Y. Lee, H. S. Shim, J. S. Kim, K. S. Kim, and I. Shim, "Chronic treatment with squid phosphatidylserine activates glucose uptake and ameliorates TMT-induced cognitive deficit in rats via activation of cholinergic systems," Evidence-Based Complementary and Alternative Medicine, vol. 2012, Article ID 601018, 8 pages, 2012.

[77] B. Lee, B.-J. Sur, J.-J. Han et al., "Oral administration of squid lecithin-transphosphatidylated phosphatidylserine improves memory impairment in aged rats," Progress in NeuroPsychopharmacology and Biological Psychiatry, vol. 56, pp. 1-10, 2015.

[78] L. Amaducci, "Phosphatidylserine in the treatment of Alzheimer's disease: results of a multicenter study," Psychopharmacology Bulletin, vol. 24, no. 1, pp. 130-134, 1988.

[79] L. Amaducci, T. H. Crook, A. Lippi et al., "Use of phosphatidylserine in Alzheimer's disease," Annals of the New York Academy of Sciences, vol. 640, pp. 245-249, 1991.

[80] T. Cenacchi, T. Bertoldin, C. Farina et al., "Cognitive decline in the elderly: a double-blind, placebo-controlled multicenter study on efficacy of phosphatidylserine administration," Aging Clinical and Experimental Research, vol. 5, no. 2, pp. 123-133, 1993.

[81] M. I. Kingsley, M. Miller, L. P. Kilduff, J. McEneny, and D. Benton, "Effects of phosphatidylserine on exercise capacity during cycling in active males," Medicine and Science in Sports and Exercise, vol. 38, no. 1, pp. 64-71, 2006.

[82] S. Hirayama, K. Terasawa, R. Rabeler et al., "The effect of phosphatidylserine administration on memory and symptoms of attention-deficit hyperactivity disorder: a randomised, doubleblind, placebo-controlled clinical trial," Journal of Human Nutrition and Dietetics, vol. 27, supplement 2, pp. 284-291, 2014.

[83] N. Tamaki, T. Kusunoki, and S. Matsumoto, "The effect of vinpocetine on cerebral blood flow in patients with cerebrovascular disorders," Therapia Hungarica, vol. 33, no. 1, pp. 13-21, 1985.

[84] N. Tamaki and S. Matsumoto, "Agents to improve cerebrovascular circulation and cerebral metabolism-vinpocetine," Nippon Rinsho, vol. 43, no. 2, pp. 376-378, 1985.

[85] P. Bönöczk, G. Panczel, and Z. Nagy, "Vinpocetine increases cerebral blood flow and oxygenation in stroke patients: a near infrared spectroscopy and transcranial Doppler study," European Journal of Ultrasound, vol. 15, no. 1-2, pp. 85-91, 2002.

[86] G. Szilágyi, Z. Nagy, L. Balkay et al., "Effects of vinpocetine on the redistribution of cerebral blood flow and glucose metabolism in chronic ischemic stroke patients: a PET study," Journal of the Neurological Sciences, vol. 229-230, pp. 275-284, 2005.

[87] C. Pereira, P. Agostinho, P. I. Moreira, A. I. Duarte, M. S. Santos, and C. R. Oliveira, "Neuroprotection strategies: effect 
of vinpocetinein in vitro oxidative stress models," Acta Medica Portuguesa, vol. 16, no. 6, pp. 401-406, 2003.

[88] C. Pereira, P. Agostinho, and C. R. Oliveira, "Vinpocetine attenuates the metabolic dysfunction induced by amyloid $\beta$ peptides in PC12 cells," Free Radical Research, vol. 33, no. 5, pp. 497-506, 2000.

[89] E. I. Solntseva, I. V. Bukanova, and V. G. Skrebitskiǔ, "Memory and potassium channels," Uspekhi Fiziologicheskikh Nauk, vol. 34, no. 4, pp. 16-25, 2003.

[90] R. T. Liu, A. Wang, E. To et al., "Vinpocetine inhibits amyloidbeta induced activation of NF- $\kappa \mathrm{B}, \mathrm{NLRP} 3$ inflammasome and cytokine production in retinal pigment epithelial cells," Experimental Eye Research, vol. 127, pp. 49-58, 2014.

[91] L. Zhang and L. Yang, "Anti-inflammatory effects of vinpocetine in atherosclerosis and ischemic stroke: a review of the literature," Molecules, vol. 20, no. 1, pp. 335-347, 2015.

[92] A. Valikovics, A. Csányi, and L. Németh, "Study of the effects of vinpocetin on cognitive functions," Ideggyogyaszati Szemle, vol. 65, no. 3-4, pp. 115-120, 2012.

[93] S. Z. Szatmari and P. J. Whitehouse, "Vinpocetine for cognitive impairment and dementia," Cochrane Database of Systematic Reviews, no. 1, Article ID CD003119, 2003.

[94] A. Valikovics, "Investigation of the effect of vinpocetine on cerebral blood flow and cognitive functions," Ideggyógyászati Szemle, vol. 60, no. 7-8, pp. 301-310, 2007.

[95] Y. Q. Liang and X. C. Tang, "Comparative effects of huperzine A, donepezil and rivastigmine on cortical acetylcholine level and acetylcholinesterase activity in rats," Neuroscience Letters, vol. 361, no. 1-3, pp. 56-59, 2004.

[96] Y.-Q. Liang and X.-C. Tang, "Comparative studies of huperzine A, donepezil, and rivastigmine on brain acetylcholine, dopamine, norepinephrine, and 5-hydroxytryptamine levels in freely-moving rats," Acta Pharmacologica Sinica, vol. 27, no. 9, pp. 1127-1136, 2006.

[97] R. Wang, H. Yan, and X.-C. Tang, "Progress in studies of huperzine $\mathrm{A}$, a natural cholinesterase inhibitor from Chinese herbal medicine," Acta Pharmacologica Sinica, vol. 27, no. 1, pp. 1-26, 2006.

[98] S.-H. Xing, C.-X. Zhu, R. Zhang, and L. An, "Huperzine A in the treatment of Alzheimer's disease and vascular dementia: a meta-analysis," Evidence-Based Complementary and Alternative Medicine, vol. 2014, Article ID 363985, 10 pages, 2014.

[99] G. T. Ha, R. K. Wong, and Y. Zhang, "Huperzine a as potential treatment of Alzheimer's disease: an assessment on chemistry, pharmacology, and clinical studies," Chemistry and Biodiversity, vol. 8, no. 7, pp. 1189-1204, 2011.

[100] N. Zhu, J. Lin, K. Wang, M. Wei, Q. Chen, and Y. Wang, "Huperzine a protects neural stem cells against $\mathrm{A} \beta$-induced apoptosis in a neural stem cells and microglia co-culture system," International Journal of Clinical and Experimental Pathology, vol. 8, no. 6, pp. 6425-6433, 2015.

[101] Z.-Q. Xu, X.-M. Liang, Juan-Wu, Y.-F. Zhang, C.-X. Zhu, and X.-J. Jiang, "Treatment with huperzine a improves cognition in vascular dementia patients," Cell Biochemistry and Biophysics, vol. 62, no. 1, pp. 55-58, 2012.

[102] J. Li, H. M. Wu, R. L. Zhou, G. J. Liu, and B. R. Dong, "Huperzine a for Alzheimer's disease," Cochrane database of Systematic Reviews, no. 2, Article ID CD005592, 2008.

[103] M. S. Rafii, S. Walsh, J. T. Little et al., "A phase II trial of huperzine A in mild to moderate Alzheimer disease," Neurology, vol. 76, no. 16, pp. 1389-1394, 2011.
[104] R. Ihl, "Gingko biloba extract EGb $761^{\circledR}$ : clinical data in dementia," International Psychogeriatrics, vol. 24, supplement 1, pp. S35-S40, 2012.

[105] S. Kasper, "Clinical data in early intervention," International Psychogeriatrics, vol. 24, supplement 1, pp. S41-S45, 2012.

[106] M. J. Serby, C. Yhap, and E. Y. Landron, "A study of herbal remedies for memory complaints," Journal of Neuropsychiatry and Clinical Neurosciences, vol. 22, no. 3, pp. 345-347, 2010.

[107] H.-J. Gertz and M. Kiefer, "Review about Ginkgo biloba special extract EGb 761 (Ginkgo)," Current Pharmaceutical Design, vol. 10, no. 3, pp. 261-264, 2004.

[108] S. Stoll, K. Scheuer, O. Pohl, and W. E. Müller, "Ginkgo biloba extract (EGb 761) independently improves changes in passive avoidance learning and brain membrane fluidity in the aging mouse," Pharmacopsychiatry, vol. 29, no. 4, pp. 144-149, 1996.

[109] C.-S. Liu, J.-F. Hu, N.-H. Chen, and J.-T. Zhang, "Comparison of the inhibitory activities of salvianolic acid B and Ginkgo biloba extract EGb 761 on neurotoxicity of beta-amyloid peptide," Yao Xue Xue Bao, vol. 41, no. 8, pp. 706-711, 2006.

[110] F. Longpré, P. Garneau, Y. christen, and C. Ramassamy, "Protection by EGb 761 against $\beta$-amyloid-induced neurotoxicity: Involvement of NF- $\kappa \mathrm{B}$, SIRT1, and MAPKs pathways and inhibition of amyloid fibril formation," Free Radical Biology and Medicine, vol. 41, no. 12, pp. 1781-1794, 2006.

[111] O. M. E. Abdel-Salam, "Stem cell therapy for Alzheimer's disease," CNS and Neurological Disorders-Drug Targets, vol. 10, no. 4, pp. 459-485, 2011.

[112] N. M. Osman, A. S. Amer, and S. Abdelwahab, "Effects of Ginko biloba leaf extract on the neurogenesis of the hippocampal dentate gyrus in the elderly mice," Anatomical Science International, 2015.

[113] L. Sun, W. Zhuang, X. Xu, J. Yang, J. Teng, and F. Zhang, "The effect of injection of EGb 761 into the lateral ventricle on hippocampal cell apoptosis and stem cell stimulation in situ of the ischemic/reperfusion rat model," Neuroscience Letters, vol. 555, pp. 123-128, 2013.

[114] F. Tchantchou, P. N. Lacor, Z. Cao et al., "Stimulation of neurogenesis and synaptogenesis by bilobalide and quercetin via common final pathway in hippocampal neurons," Journal of Alzheimer's Disease, vol. 18, no. 4, pp. 787-798, 2009.

[115] F. Tchantchou, Y. Xu, Y. Wu, Y. Christen, and Y. Luo, "EGb 761 enhances adult hippocampal neurogenesis and phosphorylation of CREB in transgenic mouse model of Alzheimer's disease," The FASEB Journal, vol. 21, no. 10, pp. 2400-2408, 2007.

[116] D. Y. Yoo, Y. Y. Nam, W. Kim et al., "Effects of ginkgo biloba extract on promotion of neurogenesis in the hippocampal dentate gyrus in C57BL/6 mice," Journal of Veterinary Medical Science, vol. 73, no. 1, pp. 71-76, 2011.

[117] R. F. Santos, J. C. F. Galduróz, A. Barbieri, M. L. V. Castiglioni, L. Y. Ytaya, and O. F. A. Bueno, "Cognitive performance, SPECT, and blood viscosity in elderly non-demented people using Ginkgo biloba," Pharmacopsychiatry, vol. 36, no. 4, pp. 127-133, 2003.

[118] S.-Y. Huang, C. Jeng, S.-C. Kao, J. J.-H. Yu, and D.-Z. Liu, "Improved haemorrheological properties by Ginkgo biloba extract (Egb 761) in type 2 diabetes mellitus complicated with retinopathy," Clinical Nutrition, vol. 23, no. 4, pp. 615-621, 2004.

[119] P. Koltringer, O. Eber, G. Klima et al., "Microcirculation under therapy of parenteral Ginkgo biloba extract," Wiener Klinische Wochenschrift, vol. 101, no. 6, pp. 198-200, 1989. 
[120] M. Esposito and M. Carotenuto, "Ginkgolide B complex efficacy for brief prophylaxis of migraine in school-aged children: an open-label study," Neurological Sciences, vol. 32, no. 1, pp. 7981, 2011.

[121] E. Nooshinfar, R. Lashgari, A. Haghparast, and S. Sajjadi, "NMDA receptors are involved in Ginkgo extract-induced facilitation on memory retention of passive avoidance learning in rats," Neuroscience Letters, vol. 432, no. 3, pp. 206-211, 2008.

[122] S. R. Veerman, P. Schulte, M. Begemann, and L. de Haan, "Nonglutamatergic clozapine augmentation strategies: a review and meta-analysis," Pharmacopsychiatry, vol. 47, no. 7, pp. 231-238, 2014.

[123] W. H. Cong, J. X. Liu, and L. Xu, "Effects of extracts of ginseng and ginkgo biloba on hippocampal acetylcholine and monoamines in pdap-pv717i transgenic mice," Zhongguo Zhong Xi Yi Jie He Za Zhi, vol. 27, no. 9, pp. 810-813, 2007.

[124] J. Kehr, S. Yoshitake, S. Ijiri, E. Koch, M. Nöldner, and T. Yoshitake, "Ginkgo biloba leaf extract (EGb 761 ${ }^{\circledR}$ ) and its specific acylated flavonol constituents increase dopamine and acetylcholine levels in the rat medial prefrontal cortex: possible implications for the cognitive enhancing properties of EGb 761 ${ }^{\circledR}$, International Psychogeriatrics, vol. 24, supplement 1, pp. S25-S34, 2012.

[125] R. Kaschel, "Specific memory effects of Ginkgo biloba extract EGb 761 in middle-aged healthy volunteers," Phytomedicine, vol. 18, no. 14, pp. 1202-1207, 2011.

[126] D. O. Kennedy, P. A. Jackson, C. F. Haskell, and A. B. Scholey, "Modulation of cognitive performance following single doses of $120 \mathrm{mg}$ Ginkgo biloba extract administered to healthy young volunteers," Human Psychopharmacology, vol. 22, no. 8, pp. 559566, 2007.

[127] J. Kulisevsky, "Role of dopamine in learning and memory: implications for the treatment of cognitive dysfunction in patients with Parkinson's disease," Drugs and Aging, vol. 16, no. 5, pp. 365-379, 2000.

[128] C. Chen, Y.-F. Zhu, and K. Wilcoxen, "An improved synthesis of selectively protected L-dopa derivatives from L-tyrosine," Journal of Organic Chemistry, vol. 65, no. 8, pp. 2574-2576, 2000.

[129] F. Panza, V. Solfrizzi, M. R. Barulli et al., "Coffee, tea, and caffeine consumption and prevention of late-life cognitive decline and dementia: a systematic review," Journal of Nutrition, Health and Aging, vol. 19, no. 3, pp. 313-328, 2015.

[130] J. Birks and J. Grimley Evans, "Ginkgo biloba for cognitive impairment and dementia," Cochrane Database of Systematic Reviews, no. 1, Article ID CD003120, 2009.

[131] S. Gauthier and S. Schlaefke, "Efficacy and tolerability of Ginkgo biloba extract EGb $761^{\circledR}$ in dementia: a systematic review and meta-analysis of randomized placebo-controlled trials," Journal of Clinical Interventions in Aging, vol. 9, pp. 2065-2077, 2014.

[132] S. Kasper and H. Schubert, "Ginkgo biloba extract EGb 761 in the treatment of dementia: evidence of efficacy and tolerability," Fortschritte der Neurologie-Psychiatrie, vol. 77, no. 9, pp. 494506, 2009.

[133] S. Weinmann, S. Roll, C. Schwarzbach, C. Vauth, and S. N. Willich, "Effects of Ginkgo biloba in dementia: systematic review and meta-analysis," BMC Geriatrics, vol. 10, article 14, 2010.

[134] T. Charemboon and K. Jaisin, "Ginkgo biloba for prevention of dementia: a systematic review and meta-analysis," Journal of the Medical Association of Thailand, vol. 98, no. 5, pp. 508-513, 2015.

[135] G. Yang, Y. Wang, J. Sun, K. Zhang, and J. Liu, "Ginkgo biloba for mild cognitive impairment and alzheimer's disease: a systematic review and meta-analysis of randomized controlled trials," Current Topics in Medicinal Chemistry, vol. 16, no. 5, pp. 520-528, 2015.

[136] B. E. Snitz, E. S. O’Meara, M. C. Carlson et al., “Ginkgo biloba for preventing cognitive decline in older adults: a randomized trial," The Journal of the American Medical Association, vol. 302, no. 24, pp. 2663-2670, 2009.

[137] H. Amieva, C. Meillon, C. Helmer, P. Barberger-Gateau, and J. F. Dartigues, "Ginkgo biloba extract and long-term cognitive decline: a 20-year follow-up population-based study," PLoS ONE, vol. 8, no. 1, Article ID e52755, 2013.

[138] J. A. Mix and W. D. Crews Jr., "An examination of the efficacy of Ginkgo biloba extract EGb 761 on the neuropsychologic functioning of cognitively intact older adults," The Journal of Alternative and Complementary Medicine, vol. 6, no. 3, pp. 219229, 2000.

[139] R. S. Doody, J. L. Cummings, and M. R. Farlow, "Reviewing the role of donepezil in the treatment of Alzheimer's disease," Current Alzheimer Research, vol. 9, no. 7, pp. 773-781, 2012.

[140] H. MacPherson, K. A. Ellis, A. Sali, and A. Pipingas, "Memory improvements in elderly women following 16 weeks treatment with a combined multivitamin, mineral and herbal supplement: a randomized controlled trial," Psychopharmacology, vol. 220, no. 2, pp. 351-365, 2012.

[141] H. Macpherson, R. Silberstein, and A. Pipingas, "Neurocognitive effects of multivitamin supplementation on the steady state visually evoked potential (SSVEP) measure of brain activity in elderly women," Physiology and Behavior, vol. 107, no. 3, pp. 346-354, 2012.

[142] V. Solfrizzi and F. Panza, "Plant-based nutraceutical interventions against cognitive impairment and dementia: metaanalytic evidence of efficacy of a standardized Gingko biloba extract," Journal of Alzheimer's Disease, vol. 43, no. 2, pp. 605611, 2015.

[143] S. Ramlall, J. Chipps, A. I. Bhigjee, and B. J. Pillay, "Screening a heterogeneous elderly South African population for cognitive impairment: the utility and performance of the mini-mental state examination, six item screener, subjective memory rating scale and deterioration cognitive observee," African Journal of Psychiatry, vol. 16, no. 6, pp. 445-455, 2013.

[144] L. Rami, M. A. Mollica, C. Garcfa-Sanchez et al., "The subjective cognitive decline questionnaire (SCD-Q): a validation study," Journal of Alzheimer's Disease, vol. 41, no. 2, pp. 453-466, 2014.

[145] L. A. Rabin, W. B. Barr, and L. A. Burton, "Assessment practices of clinical neuropsychologists in the United States and Canada: a survey of INS, NAN, and APA division 40 members," Archives of Clinical Neuropsychology, vol. 20, no. 1, pp. 33-65, 2005.

[146] B. L. Brooks, G. L. Iverson, J. A. Holdnack, and H. H. Feldman, "Potential for misclassification of mild cognitive impairment: a study of memory scores on the Wechsler Memory Scale-III in healthy older adults," Journal of the International Neuropsychological Society, vol. 14, no. 3, pp. 463-478, 2008.

[147] C. P. D'Amato and R. L. Denney, "The diagnostic utility of the rarely missed index of the wechsler memory scale-third edition in detecting response bias in an adult male incarcerated setting," Archives of Clinical Neuropsychology, vol. 23, no. 5, pp. 553-561, 2008.

[148] A. M. Seelye, D. B. Howieson, K. V. Wild, M. M. Moore, and J. A. Kaye, "Wechsler memory scale-III faces test performance in patients with mild cognitive impairment and mild Alzheimer's disease," Journal of Clinical and Experimental Neuropsychology, vol. 31, no. 6, pp. 682-688, 2009. 
[149] H. R. Sohrabi, K. A. Bates, M. Rodrigues et al., "The relationship between memory complaints, perceived quality of life and mental health in apolipoprotein e 44 carriers and non-carriers," Journal of Alzheimer's Disease, vol. 17, no. 1, pp. 69-79, 2009.

[150] P.-L. Lee, "The relationship between memory complaints, activity and perceived health status," Scandinavian Journal of Psychology, vol. 55, no. 2, pp. 136-141, 2014.

[151] K. E. Zuniga, M. J. Mackenzie, A. Kramer, and E. McAuley, "Subjective memory impairment and well-being in communitydwelling older adults," Psychogeriatrics, vol. 16, no. 1, pp. 20-26, 2016.

[152] A. Schmidt, F. Hammann, B. Wölnerhanssen et al., "Green tea extract enhances parieto-frontal connectivity during working memory processing," Psychopharmacology, vol. 231, pp. 38793888, 2014.

[153] H. Li, X. Wu, Q. Wu et al., "Green tea polyphenols protect against okadaic acid-induced acute learning and memory impairments in rats," Nutrition, vol. 30, no. 3, pp. 337-342, 2014.

[154] A. L. Lardner, "Neurobiological effects of the green tea constituent theanine and its potential role in the treatment of psychiatric and neurodegenerative disorders," Nutritional Neuroscience, vol. 17, no. 4, pp. 145-155, 2014.

[155] S. Xu and Z. Wu, "The construction of the 'clinical memory teste," Acta Psychologica Sinica, vol. 8, pp. 100-108, 1986.

[156] A. F. Jacinto, S. M. D. Brucki, C. S. Porto, M. D. A. Martins, and R. Nitrini, "Subjective memory complaints in the elderly: a sign of cognitive impairment?" Clinics, vol. 69, no. 3, pp. 194197, 2014.

[157] C. Jonker, L. J. Launer, C. Hooijer, and J. Lindeboom, "Memory complaints and memory impairment in older individuals," Journal of the American Geriatrics Society, vol. 44, no. 1, pp. 4449, 1996.

[158] E. L. Abner, R. J. Kryscio, A. M. Caban-Holt, and F. A. Schmitt, "Baseline subjective memory complaints associate with increased risk of incident dementia: the preadvise trial," The Journal of Prevention of Alzheimer's Disease, vol. 2, pp. 1116, 2015.

[159] J.-M. Kim, R. Stewart, S.-W. Kim, S.-J. Yang, I.-S. Shin, and J.S. Yoon, "A prospective study of changes in subjective memory complaints and onset of dementia in South Korea," American Journal of Geriatric Psychiatry, vol. 14, no. 11, pp. 949-956, 2006.

[160] T. Luck, S. G. Riedel-Heller, M. Luppa et al., "Risk factors for incident mild cognitive impairment-results from the german study on ageing, cognition and dementia in primary care patients (AgeCoDe)," Acta Psychiatrica Scandinavica, vol. 121, no. 4, pp. 260-272, 2010.

[161] M. Rönnlund, A. Sundström, R. Adolfsson, and L.-G. Nilsson, "Subjective memory impairment in older adults predicts future dementia independent of baseline memory performance: evidence from the Betula prospective cohort study," Alzheimer's \& Dementia, vol. 11, no. 11, pp. 1385-1392, 2015.

[162] A. B. Zonderman and T. Grimmer, "Risk of mild cognitive impairment: the olmsted county mci risk score," Neurology, vol. 84, no. 14, pp. 1392-1393, 2015.

[163] V. K. Ramanan, S. L. Risacher, K. Nho et al., "APOE and BCHE as modulators of cerebral amyloid deposition: a florbetapir PET genome-wide association study," Molecular Psychiatry, vol. 19, no. 3, pp. 351-357, 2014.

[164] M. Arbabi, N. Zhand, S. Eybpoosh, N. Yazdi, S. Ansari, and M. Ramezani, "Correlates of memory complaints and personality, depression, and anxiety in a memory clinic," Acta Medica Iranica, vol. 53, no. 5, pp. 270-275, 2015.
[165] T.Zandi, "Relationship between subjective memory complaints, objective memory performance, and depression among older adults," American Journal of Alzheimer's Disease and other Dementias, vol. 19, no. 6, pp. 353-360, 2004.

[166] M. Polyakova, N. Sonnabend, C. Sander et al., "Prevalence of minor depression in elderly persons with and without mild cognitive impairment: a systematic review," Journal of Affective Disorders, vol. 152-154, no. 1, pp. 28-38, 2014.

[167] M. Montenegro, P. Montejo, M. D. Claver-Martín et al., "Relationship between memory complaints and memory performance, mood and sociodemographic variables in young adults," Revista de Neurologia, vol. 57, no. 9, pp. 396-404, 2013.

[168] F. F. Roussotte, B. A. Gutman, S. K. Madsen, J. B. Colby, K. L. Narr, and P. M. Thompson, "The apolipoprotein E epsilon 4 allele is associated with ventricular expansion rate and surface morphology in dementia and normal aging," Neurobiology of Aging, vol. 35, no. 6, pp. 1309-1317, 2014. 


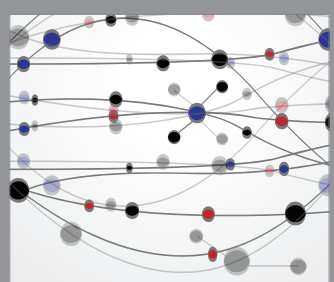

The Scientific World Journal
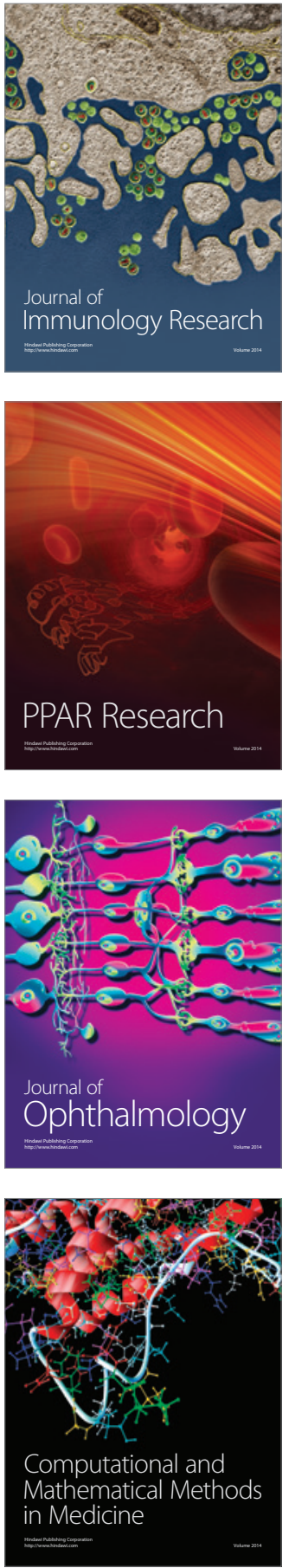

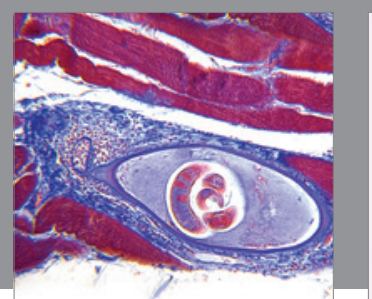

Gastroenterology Research and Practice

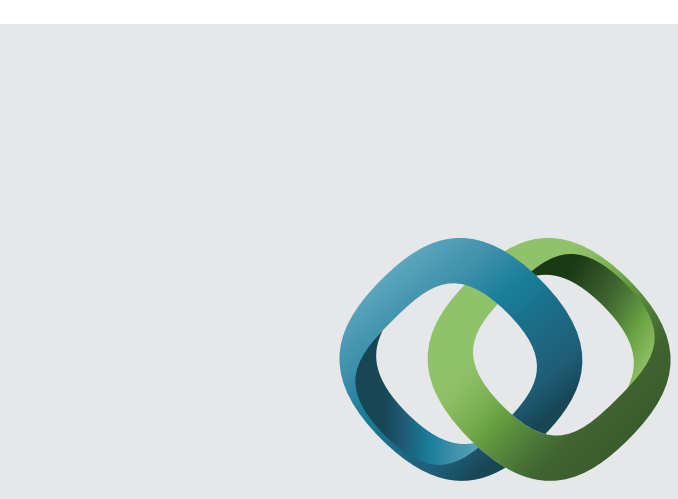

\section{Hindawi}

Submit your manuscripts at

http://www.hindawi.com
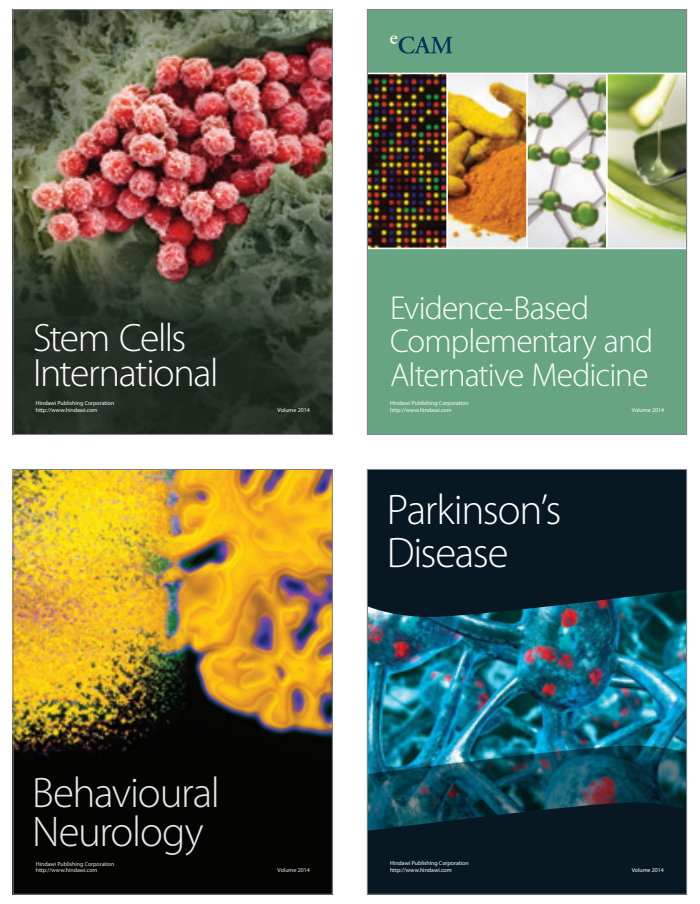
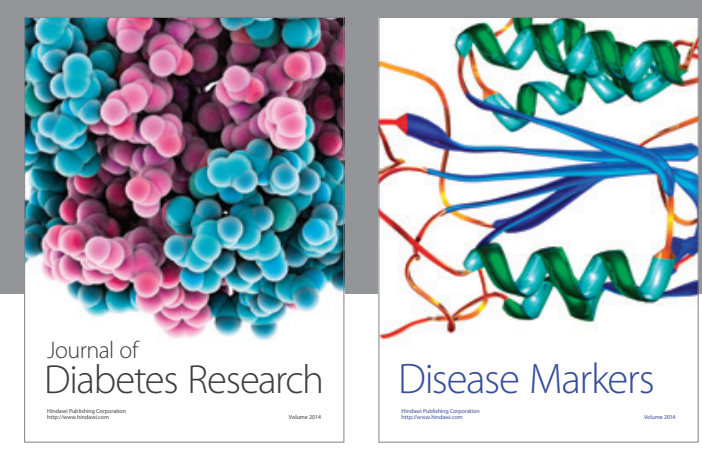

Disease Markers
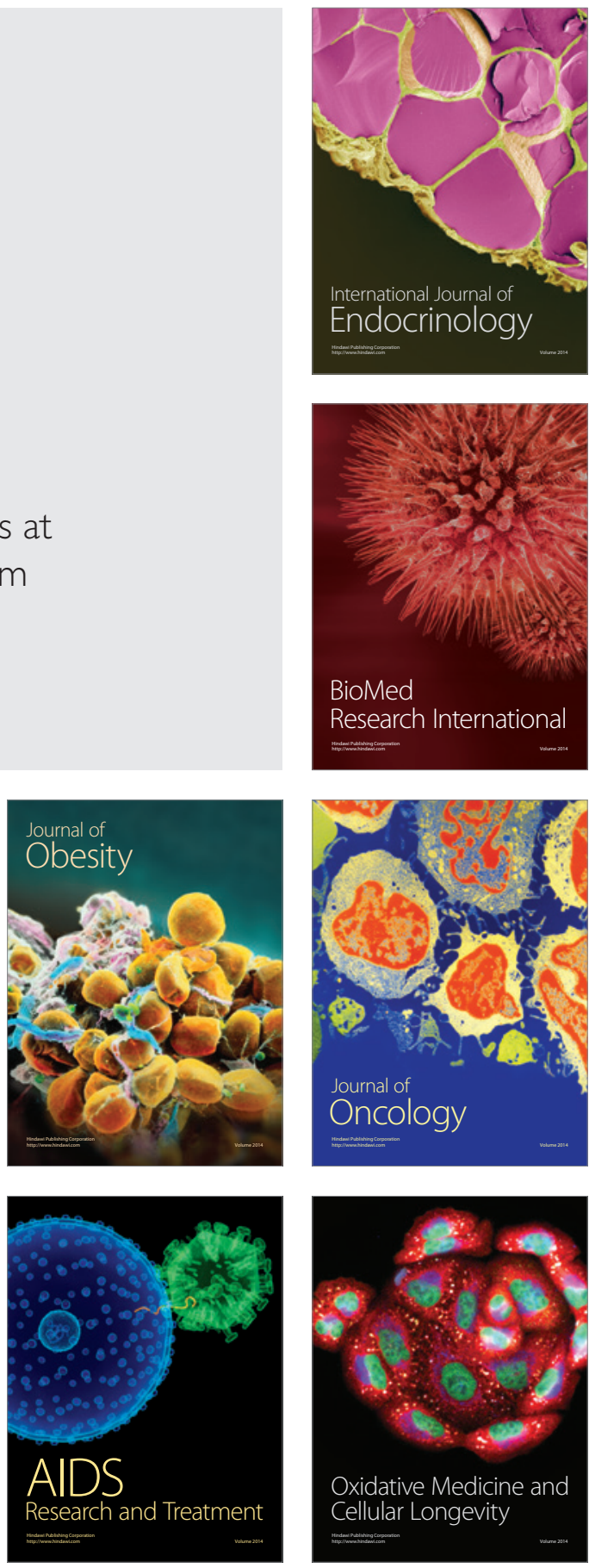